\title{
Pelletization of wood and alternative residual biomass blends for producing industrial quality pellets
}

\author{
R. García, M. V. Gil, F. Rubiera, C. Pevida \\ Instituto Nacional del Carbón, INCAR-CSIC, Francisco Pintado Fe 26, 33011 Oviedo, Spain
}

\begin{abstract}
Pellets for industrial use were produced from blends of pine sawdust (PIN) and alternative residual biomasses in a pilot-scale pelletizer. The effect of the pelletization temperature $(\mathrm{T}=50$ $\left.80{ }^{\circ} \mathrm{C}\right)$ and biomass moisture content $(\mathrm{MC}=14-20 \%)$ on pine sawdust pellet quality was studied by using response surface methodology (RSM). Pelletization performance was evaluated on the basis of the durability, bulk density, moisture content, lower heating value (LHV), energy density, diameter, length and density of the pellets. From the RSM analysis, a maximum durability value of $99.4 \%$ was obtained at $\mathrm{T}=80^{\circ} \mathrm{C}$ and $\mathrm{MC}=16.6 \%$. Under these conditions, all the parameters showed values within the required range of industrial pellet qualities, i.e., a bulk density of $616 \mathrm{~kg} / \mathrm{m}^{3}$, a pellet moisture content of $7.6 \%$, a lower heating value (as received) of $18 \mathrm{MJ} / \mathrm{kg}$, a diameter of $6.2 \mathrm{~mm}$ and a length of $23.4 \mathrm{~mm}$. Blends of pine sawdust with eleven unconventional biomass samples were then pelletized under the optimum conditions to obtain pellets for industrial use according to the categories of quality defined by ISO 17225-2. Blends of pine sawdust with almond shells (AS) and olive stones (OS) contents of up to $30 \mathrm{wt} \%$, as well as with pine cone leafs (PCL) contents of up to $15 \mathrm{wt} . \%$, produced I1 pellets. Blends of pine sawdust with coffee dregs $(\mathrm{CD})$, coffee husks $(\mathrm{CH})$ and grape pomace $(\mathrm{GP})$ proportions of up to $10 \mathrm{wt} . \%$, as well as with hazelnut shells (HS), miscanthus (MIS), pine kernel shells (PKS) and switchgrass (SG) contents of up to $15 \mathrm{wt}$.\%, and also with a PCL content of between 15 and $30 \mathrm{wt} . \%$, generated I3 class pellets. Classification was not possible for cocoa shells (CS) mixed with pine sawdust due to the low bulk density of the pellets. Energy consumption resulting from the pelletization of the blends was evaluated with values ranging from 0.09 to $0.33 \mathrm{kWh} / \mathrm{kg}$, while the pelletization of pine sawdust required $0.18 \mathrm{kWh} / \mathrm{kg}$. The addition of alternative biomass feedstocks to pine sawdust may therefore serve to reduce energy consumption in industrial pelletization.
\end{abstract}

Keywords: Pelletization; Residual biomass; Industrial pellet; Durability; Bulk density; Energy consumption

\footnotetext{
* Corresponding author. Tel.: +34 9851190 90; Fax: +34 985297662

E-mail address: victoria.gil@incar.csic.es (M. V. Gil)
} 


\section{Nomenclature}

Acronyms
AAD absolute average deviation
AI abrasion index
ar as received
AS almond shells
CD coffee dregs
$\mathrm{CH} \quad$ coffee husks
CS cocoa shells
$\mathrm{db} \quad$ dry basis
DF degrees of freedom
DUR durability
FC fixed carbon
GP grape pomace
HHV higher heating value
HS hazelnut shells
LHV lower heating value
MC moisture content
MIS miscanthus
OS olive stones
PCL pine cone leafs
PIN pine sawdust
PKS pine kernel shells
RSM response surface methodology
SG switchgrass
T temperature
VM volatile matter

Symbols
A1 EN Plus quality A1
A2 EN Plus quality A2
Adj- $R^{2} \quad$ coefficient of determination adjusted to the number of variables
B EN Plus quality B
I1 Industrial quality 1
I2 Industrial quality 2 


$\begin{array}{ll}\mathrm{I} 3 & \text { Industrial quality } 3 \\ \mathrm{~m}_{<2} & \text { mass smaller than } 2 \mathrm{~mm} \\ \mathrm{~m}_{0} & \text { initial sample mass } \\ n & \text { number of experiments } \\ x_{\mathrm{i}} & \text { polynomial independent variable } \\ y & \text { polynomial response variable } \\ y_{i, \text { cal }} & \text { calculated response } \\ y_{i, \text { exp }} & \text { experimental response } \\ \beta_{0} & \text { polynomial constant term } \\ \beta_{\mathrm{i}} & \text { polynomial linear term coefficient } \\ \beta_{\mathrm{ii}} & \text { polynomial quadratic term coefficient } \\ \beta_{\mathrm{ik}} & \text { polynomial interaction term coefficient } \\ \varepsilon & \text { polynomial residual error } \\ \eta_{\mathrm{energy}} & \text { energy density }\end{array}$

\section{Introduction}

It is widely recognized that the use of biomass for energy production provides multiple environmental benefits that contribute to the mitigation of climate change. Biomass is a renewable material that is considered as carbon neutral, since during combustion it emits the $\mathrm{CO}_{2}$ absorbed from the atmosphere during biomass growth, thereby helping to counteract the greenhouse effect.

In general, biomass materials have a high moisture content and a low bulk density, which decreases combustion performance and makes it difficult to handle, transport, store or utilize in its original form. Consequently, an increase in biomass bulk density is needed to make it more suitable for transportation over long distances and facilitate its handling and storage. Another main problem affecting the use of biomass is its lower energy density compared to that of fossil fuels. The densification of these materials into pellets (i.e., pelletization), addresses these concerns directly [1]. Pellets are made from biomass materials that are condensed under heat and pressure. The raw materials used for biomass pellet production today are mainly wood residues, including sawdust from primary and secondary wood processing industries, wood shavings and wood chips [2]. Pellets provide an excellent energy density, thereby reducing transportation and storage costs and making them competitive with fossil fuels. Furthermore, pellets are more homogeneous in size and structure than the raw biomass, an advantage that facilitates automated feeding in continuous boiler systems [3]. 
Wood pellets have come to be regarded as a reliable and concrete alternative for energy production in Europe due to increasing environmental concerns associated with fossil fuel consumption. Consequently, the production and consumption of pellets has experienced rapid growth in recent years. An effective delivery of manufactured pellets in bulk has been developed and new appliances especially adapted to the use of pellets with a high energy efficiency have been designed. Pellets are now used not only for domestic heating but also in cogeneration and in power plants by some European companies [4]. According to the European Pellet Council (EPC), global wood pellet consumption in 2016 reached 27.8 million tons, which translates into an increase of 6\%. Europe (mainly the EU28) remained the chief massive pellet consumer, accounting for almost $80 \%$ of the world's wood pellet consumption $(21.7$ million tons). With a production volume of 16.6 million tons, Europe supplied $74 \%$ of the pellets used, while it accounted for nearly $57 \%$ of global production. Most of European pellet consumption was related to heat production (residential heating, commercial heating and heat generated from CHP), which accounted for $61.8 \%$. The remaining $38.2 \%$ of wood pellets was used for power production [5].

Excellent pellet quality is essential to attain a constant and optimal combustion process and to avoid loss of efficiency and problems associated with the maintenance of the appliances. Fuels with more consistent properties make it easier to regulate the combustion process and so reduce capital and maintenance costs [6]. This is particularly important in the case of smallscale boilers and stoves designed for domestic use as their tolerance is much lower than that of boilers with larger capacities. Larger industrial-sized pellet boilers can use lower quality pellets without experiencing the same problems, as they are equipped with more sophisticated flue gas cleaning, combustion and process control systems. This explains why two pellet qualities, one for industrial and one for small-scale consumers, are available [7].

The International standard ISO 17225-2 defines the product requirements for wood pellets destined for non-industrial and industrial use [8]. The quality of wood pellets has been homogenized and guaranteed by the development of the certification scheme ENplus [9]. ENplus is a worldwide certification scheme that defines the quality requirements of pellets in line with the international standard ISO 17225-2, and it guarantees pellet quality for nonindustrial uses (heating and CHP in residential, commercial and public buildings). It defines three ENplus quality classes for pellets: A1, A2 and B. The majority of non-industrial pellets traded are of A1 quality, while A2 quality pellets are used in larger installations (>50 kW) and B quality pellets in large CHP or district heating units [10]. Table 1 provides the ENplus threshold values based on the most limiting factors of pellet quality. 
The industrial market, which uses large quantities of wood pellets for biomass-fired power plants also has certification schemes, like the Sustainable Biomass Partnership (SBP), although this is more oriented towards sustainability than towards quality. Large-scale users of pellets often have their own private quality agreements with their suppliers. Generally speaking, three industrial pellet qualities have been defined: I1, I2 and I3. In industry, the I2 quality is the most frequently employed in power stations [10]. The threshold values of the pellet properties of these pellet quality classes are also shown in Table 1.

\begin{tabular}{|c|c|c|c|c|c|c|c|}
\hline \multirow[t]{2}{*}{ Property } & \multirow[t]{2}{*}{ Unit } & \multicolumn{3}{|c|}{$\begin{array}{l}\text { Non-industrial use } \\
\text { (ENplus Handbook [9]) }\end{array}$} & \multicolumn{3}{|c|}{$\begin{array}{l}\text { Industrial use } \\
\text { (ISO 17225-2 [8]) }\end{array}$} \\
\hline & & ENplus A1 & ENplus A2 & ENplus B & I1 industrial & I2 industrial & I3 industrial \\
\hline Diameter & $\mathrm{mm}$ & $6,8( \pm 1)$ & $6,8( \pm 1)$ & $6,8( \pm 1)$ & $6,8( \pm 1)$ & $6,8,10( \pm 1)$ & $6,8,10,12( \pm 1)$ \\
\hline Length & $\mathrm{mm}$ & $\begin{array}{l}3.15-45 \\
99 \% \leq 40\end{array}$ & $\begin{array}{l}3.15-45 \\
99 \% \leq 40\end{array}$ & $\begin{array}{l}3.15-45 \\
99 \% \leq 40\end{array}$ & $3.15-40$ & $3.15-40$ & $3.15-40$ \\
\hline Moisture content & wt.\% ar & $\leq 10$ & $\leq 10$ & $\leq 10$ & $\leq 10$ & $\leq 10$ & $\leq 10$ \\
\hline Durability & $\%$ & $\geq 98.0$ & $\geq 97.5$ & $\geq 97.5$ & $\geq 97.5$ & $\geq 97.0$ & $\geq 96.5$ \\
\hline Bulk density & $\mathrm{kg} / \mathrm{m}^{3}$ ar & $600-750$ & $600-750$ & $600-750$ & $\geq 600$ & $\geq 600$ & $\geq 600$ \\
\hline Net Calorific Value & $\mathrm{MJ} / \mathrm{kg}$ ar & $\geq 16.5$ & $\geq 16.5$ & $\geq 16.5$ & $\geq 16.5$ & $\geq 16.5$ & $\geq 16.5$ \\
\hline Ash content & wt. $\%$ db & $\leq 0.7$ & $\leq 1.2$ & $\leq 2.0$ & $\leq 1.0$ & $\leq 1.5$ & $\leq 3.0$ \\
\hline $\mathrm{N}$ & wt. $\% \mathrm{db}$ & $\leq 0.3$ & $\leq 0.5$ & $\leq 1.0$ & $\leq 0.3$ & $\leq 0.3$ & $\leq 0.6$ \\
\hline$\underline{S}$ & wt. $\% \mathrm{db}$ & $\leq 0.04$ & $\leq 0.05$ & $\leq 0.05$ & $\leq 0.05$ & $\leq 0.05$ & $\leq 0.05$ \\
\hline
\end{tabular}

ar: as received; db: dry basis

As can be seen, the durability and bulk density of the pellets are main factors that affect their quality, since they are critical for handling and storage. Pellets must be durable and sufficiently strong to withstand transportation to different areas. Bulk density is an important property due to the fact that the fuel is usually fed in by volume, not weight, and variations in bulk density can have a significant effect on combustion efficiency [6]. Ash content is also an important parameter, since ashes are the residues left over after combustion is completed, and a low ash residue content is indicative of an efficient and clean combustion process.

The quality of the pellets not only depends on the type of raw material used, but also on the process variables employed during pelletization. The chemical properties of the pellet depend basically on the raw material, but the physical parameters depend mainly on the pelletizing process. For this reason, the pellet production process needs to be optimized to produce pellets with sufficient durability and energy density and with the lowest possible energy consumption during the process [11]. Two of the most important pelletization variables are temperature (T) and biomass moisture content (MC). The moisture content of the biomass sample is a significant factor during pelletization as it can affect the strength and processing speed of the pellets, and its optimal value varies depending on the type of feedstock used. An increase in MC enhances the fluidity of the sample, enabling it to overcome frictional resistance and pass through the die holes more easily. An insufficient biomass moisture content could lead 
to blockage of the die, whereas an excessively high MC might create pellets that are too soft and which break easily [12]. Furthermore, a higher pelletization temperature increases the flexibility of the material and makes it easier to press [11]. Also, at high temperatures, an increase in interfacial area between adjacent particles can be expected, resulting in greater adhesive strength due to van der Waals forces, hydrogen bonding, mechanical interlocking between fibers and particles, and inter-diffusion [1]. Due to the influence and interactions of various factors that affect the durability of pellets, the most suitable values of pelletization variables need to be determined using the optimization procedure outlined below.

Many biomass materials can be used to produce energy. Biomass fuels are obtained from different types of organic material and often derived from industrial activity residues. Pellets can be obtained from industrial wood waste and its co-products, agricultural residues, energy crops and waste products from the food industry, such as fruit shells. However, wood pellets are the most common type of pellet fuel used today [13] and they are generally made from compacted conifer wood sawdust and related wood processing residues, as well as tree tops and branches discarded during logging and thinning operations. However, power plants could burn many other types of biomass pellets without any difficulty. In the present work, the reutilization of different biomass wastes by blending them with pine sawdust (which is representative of the most conventionally used biomass) for pellet production is proposed, since this constitutes an environmentally friendly option that would contribute to the recovery of resources as well as to more effective waste management, as it would offer an environmentally friendly alternative for their disposal. In addition, the possibility of using alternative raw biomasses would help to maintain pellet production at times when wood is in short supply. Indeed, since the EU's Renewable energy directive established a binding target of $20 \%$ for final energy consumption from renewable sources, including bioenergy, by 2020, the growth in the consumption of wood residues has led to an increase in the price of wood. As a result, interest in alternative biomass fuels, ranging from materials such as wood residues of low quality to energy crops, and agricultural and forest residues, can be expected to grow rapidly [14]. The need to expand the feedstock base and to encourage the utilization of a variety of feedstocks, introduces new challenges for the pelletization process and for guaranteeing fuel pellet quality [15].

Several studies in the literature address the subject of pelletization of alternative raw biomasses as a substitute for the commonly used wood residues. These include agricultural residues or energy crops like food waste compost [12], rice straw [16-18], wheat straw [19], coconut residues [20], alfalfa [21], peanut hulls [22], coffee husks and grape waste [23], grasses (wheat straw, barley straw, corn stover and switchgrass) [24], olive tree leaves [25], pruned 
olive tree residues [26, 27], almond and cocoa shells [28] or poplar [11]. These studies are mainly focused on the effects of operating conditions during pelletization (biomass moisture content, temperature, particle size, pressure) upon the properties of the pellets. Different optimum values of biomass moisture content and process temperature are proposed, such as $35 \% \mathrm{MC}$ for food waste compost mixed with $20 \%$ of dairy powder waste additive [12], $15 \%$ $\mathrm{MC}$ and $60-80^{\circ} \mathrm{C}$ for rice straw [16] or $6.1 \%$ MC for birch [29]. For the pelletization of pine sawdust, optimum moisture content values of between 11 and $13 \%$ have been reported $[6,30]$. A few studies have focused on pellet production using blends of pine sawdust with other biomass materials (poplar [11], fruit shells [28], canary grass, timothy hay and switchgrass [31], wheat and rapeseed straws [32], beech, poplar, willow and wheat straw [33]). However, the objective of obtaining pellets of industrial quality for use in power plants has hardly been considered. The use of alternative types of biomass for producing pellets would provide additional environmental benefits as long as the obtained pellets fulfilled the required quality specifications. In order to be able to promote the use of alternative biomass feedstocks for the fabrication of industrial pellets, a better knowledge is needed of how the addition of new raw biomass materials affects pellet quality.

The objective of the present study is to investigate the effects and interactions of pelletization temperature and biomass moisture content on the quality of pine sawdust pellets in order to establish the optimum operating values for these parameters during the pelletization process at industrial scale. A multivariate technique involving the optimization of processes, the response surface methodology (RSM), was used. Pelletization performance was evaluated on the basis of pellet durability, bulk density, pellet moisture content, lower heating value, energy density, pellet diameter, length and density. These parameters are commonly used in the characterization of pellets and biomass fuels. Details can be found elsewhere [23, 28, 34, 35]. The pelletization of blends of pine sawdust with eleven alternative biomass materials was then studied in order to produce pellets for industrial use in accordance with established quality specifications. The proportion of biomass needed to obtain pellets of the highest possible industrial quality (I1, I2 and I3) was determined.

\section{Materials and methods}

\subsection{Biomass characterization}

Twelve lignocellulosic biomass samples from different origins were selected to study the pelletization process of biomass materials. These included a softwood biomass sample, pine sawdust (PIN), and eight seasonal wastes from the food industry, i.e., almond shells (AS), coffee dregs (CD), coffee husks (CH), cocoa shells (CS), grape pomace (GP), hazelnut shells 
(HS), olive stones (OS) and pine kernel shells (PKS). In addition, a forest waste, pine cone leafs (PCL), traditionally employed as a source of heat in on heaths and in stoves in rural environments in Northern Spain, was used. Also, two perennial grasses generally classified as bioenergy crops, miscanthus (MIS) and switchgrass (SG), were selected.

Ultimate and proximate analyses were performed and the higher and lower heating values (HHV and LHV, respectively) of the biomass samples were determined. Moisture and ash contents were determined in a LECO TGA701 in accordance with the ASTM D7582-10 norm, volatile matter content was evaluated in a Heraeus Electro-Nite muffle furnace following the ISO 562 norm, CHN content was analyzed in a LECO CHN2000 following the ASTM D5373 norm, and S content was determined in a LECO S632 following the ASTM D4239 norm. Higher heating values were determined in an IKA-Werke C4000 adiabatic calorimeter following the ASTM D5865 norm.

\subsection{Sample preparation}

The biomass samples were dried at $35^{\circ} \mathrm{C}$ for $72 \mathrm{~h}$, ground using a Retsch SM 2000 cutting mill and sieved to obtain a particle size below $4 \mathrm{~mm}$. The energy consumed during the grinding of a biomass sample of $100 \mathrm{~g}$ to obtain a particle size of $<4 \mathrm{~mm}$ was recorded by measuring the intensity of the electric current.

Blends of different biomass samples were analyzed in order to study the possibility of obtaining pellets that would meet the specifications established for industrial pellets. The blends of biomasses were prepared in the appropriate proportions, mixed for $2 \mathrm{~h}$ in a solids Lleal Process V-mixer mechanical blender to ensure optimal homogenization that would guarantee the right composition of mixtures. The proportion of biomass samples for each blend was configured, taking into account the $\mathrm{N}, \mathrm{S}$ and ash contents of each biomass sample, since these parameters could restrict the quantity of biomass permitted in the mixture with respect to pellet quality specifications. Table-2 shows the composition of the mixtures employed (numbers refer to wt.\% of each component) and the expected quality of the pellets which is determined by the N, S and ash contents calculated for the blends. Blends of PIN with a relatively low content of alternative biomass (10-15 wt.\%), as well as with higher proportions (20-30 wt.\%), were studied to obtain pellets of industrial quality. Due to the high ash content of GP, a smaller proportion (20 wt.\%) of this biomass was used. Moreover, due to the $\mathrm{N}$ and $\mathrm{S}$ contents of $\mathrm{CD}, \mathrm{CH}$ and CS, proportions of these samples greater than $10 \mathrm{wt} . \%$ were not used. It should also be noted that percentages higher than 15 wt.\% of HS and SG in the blends were not possible due to operational problems with the pellet press, in the form of strong vibrations that led to the complete clogging of the die holes. 


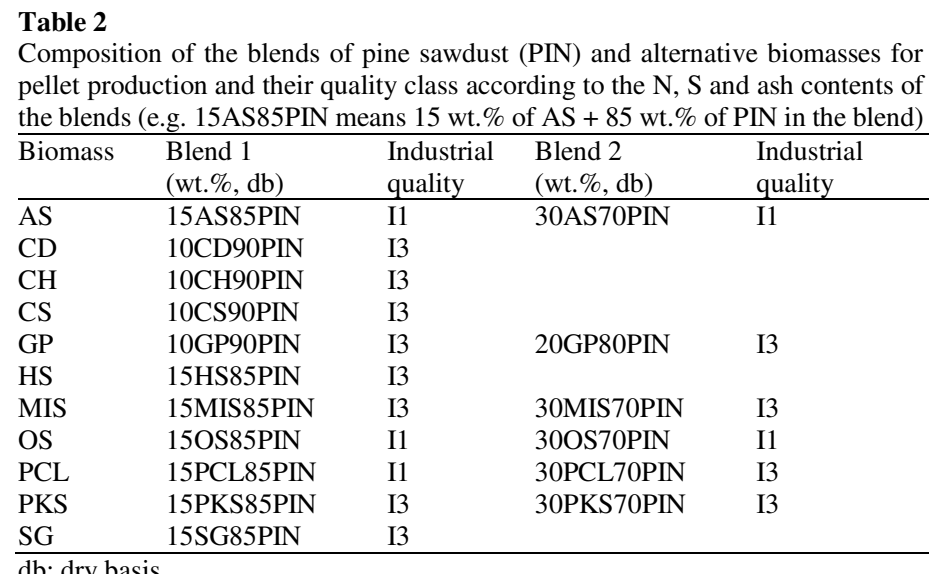

\subsection{Pelletization process}

The pellets were fabricated in an Amandus Kahl 14-175 flat die pellet press. This device is fitted with two rotating steel rollers that force the biomass sample through die holes to form the pellets. The die holes have the form of a cylinder with a diameter of $6 \mathrm{~mm}$ and a length of 30 $\mathrm{mm}$. The temperature gradually increases due to friction between the die and the powdery biomass and between the particles until a stable pelletization temperature is reached. Temperature is measured by means of a thermocouple located in the outer part of the flat die. The press can produce up to $50 \mathrm{~kg} / \mathrm{h}$ of pellets by exerting a pressure of 13 bar with the steel rollers, according to its specifications. For the feedstocks employed in the present work, each run lasted from 30 to 45 min depending on the properties of the biomass. Two cutting knives are located $35 \mathrm{~mm}$ under the die to slice the pellets as they emerge from the die holes. The pellets are then collected in a recipient. The quantity of pellets produced in each run can range from 5 to $14 \mathrm{~kg}$. After leaving the pelletizer the pellets are left to cool down to room temperature during $48 \mathrm{~h}$ in order to improve their durability and moisture content. The pellet press works in a continuous mode that simulates the operation of the pelletizers commonly used in industry, unlike a single pellet press, which applies extremely high pressures directly to a specific point on a small surface area.

In the present work, the pelletization temperature range selected was between 50 and $80{ }^{\circ} \mathrm{C}$, while biomass moisture content at the inlet of the pellet press ranged between 14 and $20 \%$. The biomass moisture content of the samples required for the pelletization process was adjusted by spraying distilled water onto the biomasses. For this purpose, the appropriate biomass moisture content was determined using an Ohaus MB45 moisture analyzer.

Furthermore, the energy consumed by the pellet press was determined during the pelletization of pine sawdust and all of the biomass blends under the best possible established 
conditions. To this end, the average power of the electrical current used by the device was obtained from five measurements taken at uniform intervals during the pelletization process.

\subsection{Pellet characterization}

Pellet quality was measured on the basis of the following parameters: durability (DUR), bulk density, pellet moisture content, lower heating value as received ( $\left.\mathrm{LHV}_{\mathrm{ar}}\right)$, i.e., taking into account the humidity of the sample, energy density as received ( $\left.\eta_{\text {energy ar }}\right)$, and pellet diameter, length and density.

To evaluate the mechanical or abrasive resistance of the pellets, a durability test was carried out in a specially designed rotating drum, as described in detail in previous works [23, 36]. A sample of approximately $100 \mathrm{~g}$ of pellets was introduced into the rotating drum and subjected to 3000 turns at $35 \mathrm{rpm}$. After each test, the sample material was screened using a $2 \mathrm{~mm}$ sieve, and particles smaller than $2 \mathrm{~mm}$ were weighed. The abrasion index, AI, was calculated as the mass percentage of pellets below $2 \mathrm{~mm}$ relative to the total initial sample mass after 3000 revolutions in the rotary drum, as shown in Eq. (1). The durability of the sample was then determined by Eq. (2):

$$
\begin{aligned}
& \mathrm{AI}=\left(\mathrm{m}_{<2} / \mathrm{m}_{0}\right) \cdot 100 \\
& \mathrm{DUR}=100-\mathrm{AI}
\end{aligned}
$$

where $\mathrm{m}_{<2}$ is the mass of the particles smaller than $2 \mathrm{~mm}$ and $\mathrm{m}_{0}$ is the initial sample mass. Thus, the higher the AI values are, the lower the mechanical resistance of the pellet, and the higher the DUR is, the better the quality of the pellet.

Bulk density measures the extent of the compaction of the particles in the pellet, and it is calculated as the weight of pellets per volume unit $\left(\mathrm{kg} / \mathrm{m}^{3}\right)$. It was determined using an Autotap tapped density analyzer from Quantachrome Instruments, which allows the mass of the sample to be related to the volume that it occupies in the test tube after 300 taps.

The moisture content of the pellets was determined after drying the pellet samples in an oven at $105^{\circ} \mathrm{C}$ to constant weight.

The LHV reflects the energy content of the pellet. The energy density, $\eta_{\text {energy ar }}\left(\mathrm{MJ} / \mathrm{m}^{3}\right)$, of the pellet samples was calculated by multiplying the $\mathrm{LHV}_{\mathrm{ar}}(\mathrm{MJ} / \mathrm{kg})$ value by the bulk density $\left(\mathrm{kg} / \mathrm{m}^{3}\right)$ value.

The diameter and length of a sample of 20 randomly selected pellets were measured using a gauge and then average values were obtained [37]. Likewise, pellet density was determined from the dimensions and weight of the samples. Pellet density was calculated from the ratio between the mass of the sample and its volume including the volume of the porosity. The mass of the pellet was measured using an electronic balance, while the volume of each pellet was 
taken as the volume of a cylinder whose dimensions (diameter and length) had been previously measured $[12,26]$.

\subsection{Response surface methodology}

Response surface methodology (RSM) was used to simultaneously optimize the pelletization variables of pine sawdust to ensure the best process performance [38]. The pelletization temperature $(\mathrm{T})$ and biomass moisture content (MC) were the independent variables evaluated to determine the optimum values that would maximize pellet quality. The response or dependent variables related to the pellet quality measured during the experiments were DUR, bulk density, pellet moisture content, $\mathrm{LHV}_{\mathrm{ar}}, \eta_{\text {energy ar }}$, and pellet diameter, length and density.

The experimental design employed was a three-level full factorial design, involving 13 experiments, as shown in Table 3, including nine factorial points and four additional replicates at the center of the design that were used to estimate the experimental error associated with the repetitions. The levels of the independent variables are the different values at which the experiments were carried out on the basis of the experimental design. In this study, the two independent variables were investigated at three levels. The pelletization temperature was studied at 50, 65 and $80^{\circ} \mathrm{C}$, while biomass moisture content was evaluated at 14,17 and $20 \%$. The experiments were conducted in random order. The levels of the independent variables were coded using dimensionless values $(-1,0$ and +1$)$, so that variables with different units or of different orders of magnitude could be compared. The responses would then be evenly affected, making the units of the parameters irrelevant. The coded values (in parentheses) and the decoded values of the independent variables ( $T$ and $M C$ ) are shown in Table 3. The experimental results obtained for the response variables are also reported in Table 3.

The mathematical-statistical treatment of the experimental data consisted in fitting a polynomial function to the set of data [39]. In this work, for two independent variables, $x_{1}(\mathrm{~T})$ and $x_{2}$ (MC), the following second-order polynomial model was employed:

$$
y=\beta_{0}+\beta_{1} x_{1}+\beta_{2} x_{2}+\beta_{12} x_{1} x_{2}+\beta_{11} x_{1} x_{1}+\beta_{22} x_{2} x_{2}+\varepsilon
$$

where $y$ is the response variable, $\beta_{0}$ is the constant term, $\beta_{1}$ and $\beta_{2}$ are the coefficients of the linear terms, $\beta_{12}$ is the coefficient of the interaction term, $\beta_{11}$ and $\beta_{22}$ are the coefficients of the quadratic terms and $\varepsilon$ is the residual associated with the experiments. Eq. (3) was fitted to the experimental data by multiple regression analysis (least squares method) and the $\beta$ coefficients that generate the lowest possible residual were determined. The equation obtained describes the response in the experimental region studied as a function of the independent variables. 
Table 3

Levels of the independent variables, i.e., pelletization temperature (T) and biomass moisture content (MC), for the pelletization of pine sawdust using a three-level full factorial design together with the experimental results obtained for the response variables studied

\begin{tabular}{|c|c|c|c|c|c|c|c|c|c|c|c|}
\hline \multirow[t]{2}{*}{$\overline{\text { Run }}$} & \multicolumn{2}{|l|}{ Factors } & \multicolumn{8}{|c|}{ Response variables } & \multirow{2}{*}{$\begin{array}{l}\text { Industrial } \\
\text { quality }\end{array}$} \\
\hline & $\mathrm{T}\left({ }^{\circ} \mathrm{C}\right)$ & $\mathrm{MC}(\%)$ & DUR (\%) & $\begin{array}{l}\text { Bulk } \\
\text { density } \\
\left(\mathrm{kg} / \mathrm{m}^{3}\right)\end{array}$ & $\begin{array}{l}\text { Pellet } \\
\text { moisture } \\
\text { content } \\
(\text { wt. } \%) \\
\end{array}$ & $\begin{array}{l}\mathrm{LHV}_{\mathrm{ar}} \\
(\mathrm{MJ} / \mathrm{kg})\end{array}$ & $\begin{array}{l}\eta_{\text {energy ar }} \\
\left(\mathrm{MJ} / \mathrm{m}^{3}\right)\end{array}$ & $\begin{array}{l}\text { Diameter } \\
(\mathrm{mm})\end{array}$ & $\begin{array}{l}\text { Length } \\
(\mathrm{mm})\end{array}$ & $\begin{array}{l}\text { Pellet } \\
\text { density } \\
\left(\mathrm{g} / \mathrm{cm}^{3}\right)\end{array}$ & \\
\hline 1 & $50(-1)$ & $14(-1)$ & 98.63 & 624 & 8.86 & 17.617 & 10990 & 6.18 & 21.66 & 1.19 & I1 \\
\hline 2 & $50(-1)$ & $17(0)$ & 98.13 & $509 *$ & $12.61 *$ & 16.878 & 8599 & 6.47 & 22.32 & 1.03 & - \\
\hline 3 & $50(-1)$ & $20(+1)$ & $91.58^{*}$ & $459 *$ & $13.19^{*}$ & 16.700 & 7662 & 6.35 & 26.27 & 1.01 & - \\
\hline 4 & $65(0)$ & $14(-1)$ & 99.13 & 667 & 6.99 & 18.015 & 12010 & 6.18 & 21.26 & 1.26 & $\mathrm{I} 1$ \\
\hline 5 & $65(0)$ & $17(0)$ & 99.15 & $592 *$ & 9.26 & 17.916 & 10610 & 6.32 & 24.26 & 1.02 & - \\
\hline 6 & $65(0)$ & $20(+1)$ & $96.48 *$ & $470 *$ & $11.43^{*}$ & 17.210 & 8089 & 6.32 & 27.16 & 1.03 & - \\
\hline 7 & $80(+1)$ & $14(-1)$ & 99.24 & 628 & 6.80 & 18.137 & 11393 & 6.15 & 21.47 & 1.23 & I1 \\
\hline 8 & $80(+1)$ & $17(0)$ & 99.28 & 671 & 6.75 & 18.174 & 12193 & 6.08 & 21.99 & 1.27 & I1 \\
\hline 9 & $80(+1)$ & $20(+1)$ & 97.92 & $512 *$ & $10.64 *$ & 17.199 & 8799 & 6.35 & 25.76 & 1.02 & - \\
\hline 10 & $65(0)$ & $17(0)$ & 98.60 & $561 *$ & 9.48 & 17.426 & 9775 & 6.31 & 21.17 & 1.11 & - \\
\hline 11 & $65(0)$ & $17(0)$ & 98.69 & $543 *$ & 9.64 & 17.519 & 9509 & 6.28 & 25.26 & 1.10 & - \\
\hline 12 & $65(0)$ & $17(0)$ & 98.81 & 600 & 10.00 & 17.337 & 10402 & 6.32 & 26.63 & 1.07 & I1 \\
\hline 13 & $65(0)$ & $17(0)$ & 98.99 & $575^{*}$ & 8.47 & 17.663 & 10164 & 6.33 & 22.51 & 1.13 & - \\
\hline
\end{tabular}

T: temperature; MC: moisture content; DUR: durability; LHV: lower heating value; $\eta_{\text {energy: energy density }}$

*: does not fulfill specifications

The statistical significance of the models was evaluated by analysis of variance (ANOVA). The $p$-value parameter was used to establish whether a model or parameter was significant, i.e., $p$-value $<0.05$ for a confidence level of $95 \%$. A significant $p$-value indicates that a regression model is suitable for describing the observed data. The non-significant terms are then eliminated and the statistical analysis repeated in order to obtain the best reduced model for each of the response variables. The accuracy of the fitted polynomial model was expressed by the determination coefficient adjusted to the number of variables $\left(\operatorname{Adj}-R^{2}\right)$ and the absolute average deviation (AAD). Adj- $R^{2}$ represents the proportion of variability of the data that is accounted for by the model. ADD is a parameter that describes the deviation between the experimental and calculated values and it is determined by the following equation [40]:

$$
\operatorname{AAD}(\%)=100\left[\sum_{i=1}^{n}\left(\frac{\left|y_{i, \exp }-y_{i, \text { calc }}\right|}{y_{i, \text { exp }}}\right)\right] / n
$$

where $y_{i, \text { exp }}$ and $y_{i, \text { cal }}$ are the experimental and calculated responses, respectively, and $n$ is the number of experiments. The statistical analyses were performed using SPSS Statistics 25 software.

The model obtained can be three-dimensionally represented as a surface (response surface plot) allowing the best operational conditions inside the studied experimental region to be visualized. The two-dimensional display of the surface plot generates the contour plot, where the lines of constant response are drawn on the plane of the two independent variables. Response surface and contour plots were generated using SigmaPlot 14.0 software. Then the optimum values for each independent variable that optimize the response in the experimental region under study were obtained. 


\section{Results and discussion}

\subsection{Effect of temperature and biomass moisture content on pellet quality}

The biomass characterization results, including the ultimate and proximate analyses, as well as the heating values (HHV and LHV), of the biomass samples are presented in Table 4.

Table 4

\begin{tabular}{|c|c|c|c|c|c|c|c|c|c|c|c|}
\hline \multirow{3}{*}{ Sample } & \multirow{2}{*}{\multicolumn{5}{|c|}{$\begin{array}{l}\text { Ultimate analysis } \\
\text { (wt.\%, db) }\end{array}$}} & \multicolumn{4}{|c|}{ Proximate analysis } & \multirow{3}{*}{$\begin{array}{l}\text { HHV } \\
\left(\mathrm{MJ} \mathrm{kg}^{-1}, \mathrm{db}\right)\end{array}$} & \multirow{3}{*}{$\begin{array}{l}\text { LHV } \\
\left(\mathrm{MJ} \mathrm{kg}^{-1}, \text { ar }\right)\end{array}$} \\
\hline & & & & & & \multirow{2}{*}{$\begin{array}{l}\text { (wt.\%) } \\
\text { MC }\end{array}$} & \multicolumn{3}{|c|}{ (wt.\%, db) } & & \\
\hline & $\mathrm{C}$ & $\mathrm{N}$ & $\mathrm{H}$ & $\mathrm{S}$ & $\mathrm{O}^{\mathrm{a}}$ & & Ash & VM & $\mathrm{FC}^{\mathrm{a}}$ & & \\
\hline$\overline{\mathrm{AS}}$ & 49.44 & 0.31 & 5.85 & 0.05 & 42.90 & 6.52 & 1.45 & 78.90 & 19.65 & 19.565 & 17.168 \\
\hline $\mathrm{CD}$ & 47.98 & 3.55 & 5.67 & 0.27 & 33.95 & 7.18 & 8.58 & 70.23 & 21.19 & 19.389 & 16.918 \\
\hline $\mathrm{CH}$ & 49.55 & 2.96 & 6.12 & 0.22 & 36.98 & 8.38 & 4.17 & 79.16 & 16.67 & 20.189 & 17.348 \\
\hline $\mathrm{CS}$ & 47.96 & 2.74 & 5.93 & 0.21 & 35.26 & 6.70 & 7.90 & 70.40 & 21.70 & 19.067 & 16.655 \\
\hline GP & 45.50 & 1.82 & 5.05 & 0.17 & 34.73 & 11.60 & 12.73 & 67.60 & 19.67 & 18.682 & 15.600 \\
\hline HS & 52.27 & 0.50 & 5.69 & 0.13 & 40.47 & 13.61 & 0.94 & 75.83 & 23.23 & 18.644 & 15.099 \\
\hline MIS & 47.96 & 0.40 & 5.79 & 0.11 & 36.74 & 5.60 & 9.00 & 77.58 & 13.42 & 18.682 & 16.515 \\
\hline OS & 51.21 & 0.29 & 6.01 & 0.03 & 41.88 & 4.32 & 0.58 & 81.50 & 17.92 & 20.511 & 18.446 \\
\hline PCL & 52.89 & 0.44 & 6.06 & 0.03 & 39.46 & 10.12 & 1.12 & 76.50 & 22.38 & 20.976 & 17.737 \\
\hline PIN & 51.02 & 0.27 & 6.04 & 0.02 & 42.23 & 9.58 & 0.42 & 85.05 & 14.53 & 19.904 & 16.878 \\
\hline PKS & 52.32 & 0.62 & 6.21 & 0.05 & 38.99 & 9.37 & 1.81 & 78.40 & 19.79 & 20.767 & 17.667 \\
\hline SG & 47.80 & 0.80 & 5.70 & 0.10 & 41.00 & 12.40 & 4.60 & 79.70 & 15.70 & 18.970 & 15.594 \\
\hline
\end{tabular}
db: dry basis; ar: as received

MC: moisture content; VM: volatile matter; FC: fixed carbon; HHV: higher heating value; LHV: lower heating value ${ }^{\text {a }}$ Determined by difference

As mentioned above, the experimental values obtained for the response variables are shown in Table 3. Eq. (3) was fitted to the experimental data by multiple regression analysis and the ANOVA tests showed which terms of the model were statistically significant for a confidence level of $95 \%$ ( $p$-value<0.05). The terms not statistically significant were eliminated from the models. The results of the fitting of the reduced model to the experimental data by multiple regression analysis, as well as the results of the statistical evaluation of the model obtained by applying ANOVA, together with the Adj- $R^{2}$ and AAD values, are shown in Table 5.

The final models obtained were statistically significant for a confidence level of $95 \%$ ( $p$ value $<0.05$ ). The coded coefficient values for the reduced models were further decoded in order to obtain polynomial models for the response variables as a function of the real independent variables, which are represented by Eqs. (5)-(12). Then, the response surface and contour plots for the variables studied were obtained. These are shown in Figs. 1-3.

$$
\text { DUR }(\%)=85.095-0.448 \mathrm{~T}+3.497 \mathrm{MC}+0.032 \mathrm{~T} \cdot \mathrm{MC}-0.181 \mathrm{MC}^{2}
$$

Bulk density $\left(\mathrm{kg} / \mathrm{m}^{3}\right)=863.901+2.429 \mathrm{~T}-26.571 \mathrm{MC}$

Pellet moisture content $(\%)=5.200+0.116 \mathrm{~T}-0.701 \mathrm{MC}$

$$
\begin{aligned}
& \mathrm{LHV}_{\text {ar }}(\mathrm{MJ} / \mathrm{kg})=18.363+0.026 \mathrm{~T}-0.148 \mathrm{MC} \\
& \eta_{\text {energy ar }}\left(\mathrm{MJ} / \mathrm{m}^{3}\right)=15603.948+57.037 \mathrm{~T}-546.842 \mathrm{MC} \\
& \text { Diameter }(\mathrm{mm})=6.095-0.005 \mathrm{~T}+0.029 \mathrm{MC} \\
& \text { Length }(\mathrm{mm})=9.677+0.823 \mathrm{MC}
\end{aligned}
$$


Table 5

Results of multiple regression analysis and ANOVA for durability (DUR), bulk density, lower heating value (LHV $\left.{ }_{\text {ar }}\right)$, energy density ( $\eta_{\text {energy }}$ ar), pellet moisture content, pellet diameter, pellet length and pellet density, after the elimination of all the non-significant terms

\begin{tabular}{|c|c|c|c|c|c|c|c|c|c|}
\hline & $\begin{array}{l}\text { Coded } \\
\text { coefficient }\end{array}$ & $\begin{array}{l}\text { Sum of } \\
\text { squares }\end{array}$ & DF & $p$-value & & $\begin{array}{l}\text { Coded } \\
\text { coefficient }\end{array}$ & $\begin{array}{l}\text { Sum of } \\
\text { squares }\end{array}$ & $\mathrm{DF}$ & $p$-value \\
\hline & \multicolumn{4}{|l|}{ DUR $(\%)$} & \multicolumn{5}{|c|}{ Pellet moisture content (\%) } \\
\hline Model & & 47.340 & 4 & 0.000 & Model & & 44.772 & 2 & 0.000 \\
\hline Intersection & 98.016 & 67249.381 & 1 & 0.000 & Intersection & 9.548 & 1185.060 & 1 & 0.000 \\
\hline $\mathrm{T}$ & 1.340 & 10.775 & 1 & 0.002 & $\mathrm{~T}$ & -1.745 & 18.270 & 1 & 0.000 \\
\hline MC & -1.821 & 19.901 & 1 & 0.000 & $\mathrm{MC}$ & 2.102 & 26.502 & 1 & 0.000 \\
\hline $\mathrm{T} \cdot \mathrm{MC}$ & 1.421 & 8.081 & 1 & 0.004 & Residual & & 6.462 & 10 & \\
\hline $\mathrm{MC}^{2}$ & -1.630 & 8.582 & 1 & 0.003 & Total & & 51.234 & 12 & \\
\hline Residual & & 3.971 & 8 & & $R^{2}$ & 0.874 & & & \\
\hline Total & & 51.311 & 12 & & $\operatorname{Adj}-R^{2}$ & 0.849 & & & \\
\hline$R^{2}$ & 0.923 & & & & $\mathrm{AAD}(\%)$ & 6.53 & & & \\
\hline $\operatorname{Adj}-R^{2}$ & 0.884 & & & & & & & & \\
\hline \multirow[t]{2}{*}{$\mathrm{AAD}(\%)$} & 0.85 & & & & & & & & \\
\hline & \multicolumn{4}{|c|}{ Bulk density $\left(\mathrm{kg} / \mathrm{m}^{3}\right)$} & \multicolumn{5}{|c|}{ Diameter $(\mathrm{mm})$} \\
\hline Model & & 46086.287 & 2 & 0.000 & Model & & 0.074 & 2 & 0.017 \\
\hline Intersection & 570.063 & 4224635.194 & 1 & 0.000 & Intersection & 6.278 & 512.448 & 1 & 0.000 \\
\hline $\mathrm{T}$ & 36.430 & 7962.661 & 1 & 0.025 & $\mathrm{~T}$ & -0.070 & 0.029 & 1 & 0.048 \\
\hline $\mathrm{MC}$ & -79.712 & 38123.625 & 1 & 0.000 & $\mathrm{MC}$ & 0.086 & 0.044 & 1 & 0.020 \\
\hline Residual & & 11408.470 & 10 & & Residual & & 0.058 & 10 & \\
\hline Total & & 57494.756 & 12 & & Total & & 0.132 & 12 & \\
\hline$R^{2}$ & 0.802 & & & & $R^{2}$ & 0.559 & & & \\
\hline $\operatorname{Adj}-R^{2}$ & 0.762 & & & & $\operatorname{Adj}-R^{2}$ & 0.471 & & & \\
\hline \multirow[t]{2}{*}{$\mathrm{AAD}(\%)$} & 4.04 & & & & $\mathrm{AAD}(\%)$ & 1.07 & & & \\
\hline & \multicolumn{4}{|c|}{$\mathrm{LHV}_{\mathrm{ar}}(\mathrm{MJ} / \mathrm{kg})$} & & \multicolumn{4}{|c|}{ Length (mm) } \\
\hline Model & & 2.070 & 2 & 0.000 & $\overline{\text { Model }}$ & & 36.581 & 1 & 0.002 \\
\hline Intersection & 17.522 & 3991.454 & 1 & 0.000 & Intersection & 23.668 & 7282.549 & 1 & 0.000 \\
\hline $\mathrm{T}$ & 0.386 & 0.892 & 1 & 0.002 & MC & 2.469 & 36.581 & 1 & 0.002 \\
\hline $\mathrm{MC}$ & -0.443 & 1.179 & 1 & 0.001 & Residual & & 25.380 & 11 & \\
\hline Residual & & 0.493 & 10 & & Total & & 61.960 & 12 & \\
\hline Total & & 2.564 & 12 & & $R^{2}$ & 0.590 & & & \\
\hline$R^{2}$ & 0.808 & & & & $\operatorname{Adj}-R^{2}$ & 0.553 & & & \\
\hline $\operatorname{Adj}-R^{2}$ & 0.769 & & & & $\mathrm{AAD}(\%)$ & 2.83 & & & \\
\hline \multirow[t]{2}{*}{$\mathrm{AAD}(\%)$} & 0.90 & & & & & & & & \\
\hline & \multicolumn{4}{|c|}{$\eta_{\text {energy ar }}\left(\mathrm{MJ} / \mathrm{m}^{3}\right)$} & & \multicolumn{4}{|c|}{ Pellet density $\left(\mathrm{g} / \mathrm{cm}^{3}\right)$} \\
\hline Model & & 20539751.414 & 2 & 0.000 & Model & & 0.066 & 1 & 0.002 \\
\hline Intersection & 9912.753 & 10015.001 & 1 & 0.000 & Intersection & 1.113 & 16.091 & 1 & 0.000 \\
\hline $\mathrm{T}$ & 835.977 & 855.548 & 1 & 0.011 & MC & -0.105 & 0.066 & 1 & 0.002 \\
\hline $\mathrm{MC}$ & -1680.378 & -1640.527 & 1 & 0.000 & Residual & & 0.045 & 11 & \\
\hline Residual & & 4602450.562 & 10 & & Total & & 0.111 & 12 & \\
\hline Total & & 25142201.976 & 12 & & $R^{2}$ & 0.594 & & & \\
\hline$R^{2}$ & 0.817 & & & & $\operatorname{Adj}-R^{2}$ & 0.557 & & & \\
\hline $\operatorname{Adj}-R^{2}$ & 0.780 & & & & $\mathrm{AAD}(\%)$ & 4.35 & & & \\
\hline AAD (\%) & 4.67 & & & & & & & & \\
\hline
\end{tabular}

ar: as received

DF: degrees of freedom; T: temperature; MC: moisture content; AAD: absolute average deviation

Table 5 shows that durability depends directly on T and inversely on MC, but a significant interaction effect between these variables was also detected (T·MC term). The quadratic term $\mathrm{MC}^{2}$ was also shown to be statistically significant. Bulk density, lower heating value and energy density depend directly on $\mathrm{T}$ and inversely on MC. Table 5 also shows that pellet moisture content and the diameter of the pellet depend inversely on T and directly on MC. Moreover, the length of the pellet depends directly on MC, while pellet density depends inversely on MC.

The coefficient values of the polynomial models in Table 5 are coded coefficients since the values of the independent variables from which they were derived were also coded. The use of 
coded coefficients makes it possible to compare the relative influence of the different factors upon the response variables. The absolute values of the coded coefficients show that the influence of $\mathrm{MC}$ is higher than that of $\mathrm{T}$ upon all the variables studied. This demonstrates that the moisture content of the biomass plays a crucial role in the pelletization process. It has also been reported in the literature that biomass moisture content has an important influence on pellet quality since water can act both as a binding agent and as a lubricant that reduces friction in the die $[1,30]$.

Durability evaluates the mechanical resistance of the pellets during storage, crushing or transportation. Abrasion is one of the most important pellet parameters, since a large amount of fines in the storage system of the end user could lead to failures in the feeding system [4]. Figs. $1 \mathrm{a}$ and $1 \mathrm{~b}$ show the effect of interaction between $\mathrm{T}$ and MC. It can be seen that the effect of each of these variables on durability varies over the range of values of the second variable. Thus, when MC values are close to $14 \%$, durability is almost constant at any $\mathrm{T}$ value, whereas for higher values of MC, DUR increases, as T increases. An increase in pellet durability with temperature has also been reported in the literature [21]. Likewise, when $\mathrm{T}$ values are close to $50^{\circ} \mathrm{C}$, DUR decreases with MC, while at higher T values, DUR increases with MC until it reaches a maximum, after which it decreases if $\mathrm{MC}$ increases any further. This is also represented by the curvature in the response surface and the contour plot isolines, which indicate that the effect of the biomass moisture content on durability varies over the experimental range of this variable studied. It has also been reported that pellet durability increases with increasing biomass moisture content until an optimum is reached and then it decreases for higher biomass moisture contents [22]. In the present study, a maximum value of durability (99.4\%) was obtained using a pelletization temperature of $80{ }^{\circ} \mathrm{C}$ and a biomass moisture content of $16.6 \%$. Moreover, it can be seen that the maximum durability value obtained-shifts towards lower biomass moisture contents when lower pelletization temperatures are used. Water is believed to be actively involved in the binding mechanism since water molecules can act as bridges between binding active sites on the particle surfaces, thereby increasing durability. If the biomass moisture content is too low, gaps where water molecules could form a bridge are not filled up and the binding strength is weakened. On the other hand, if the biomass moisture content is too high, water will attack the hydrogen bonds between the particles, resulting in a decrease in durability [30]. For these reasons, pellets obtained using a high biomass moisture content (and a low temperature) were more unstable and easily disintegrated in the present work. 
(a)

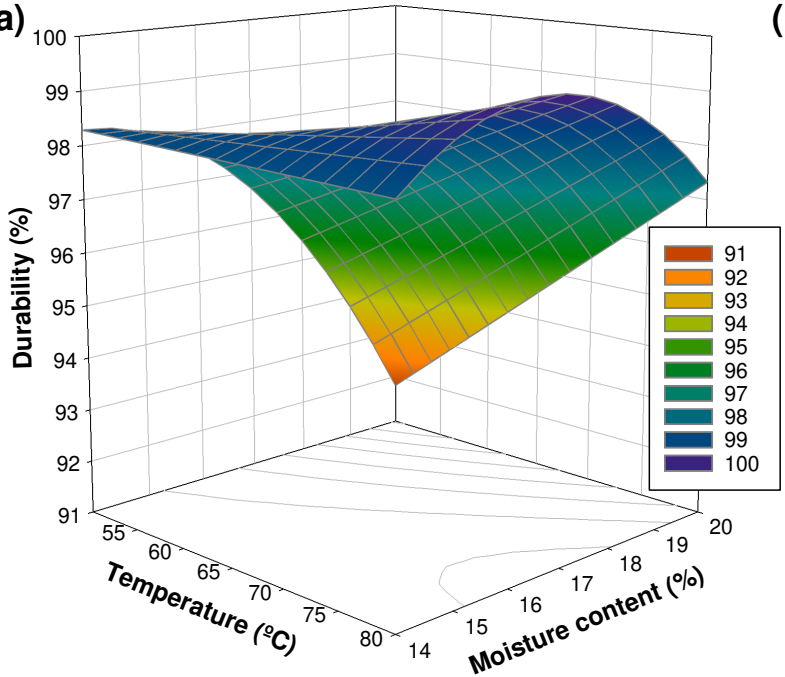

(c)

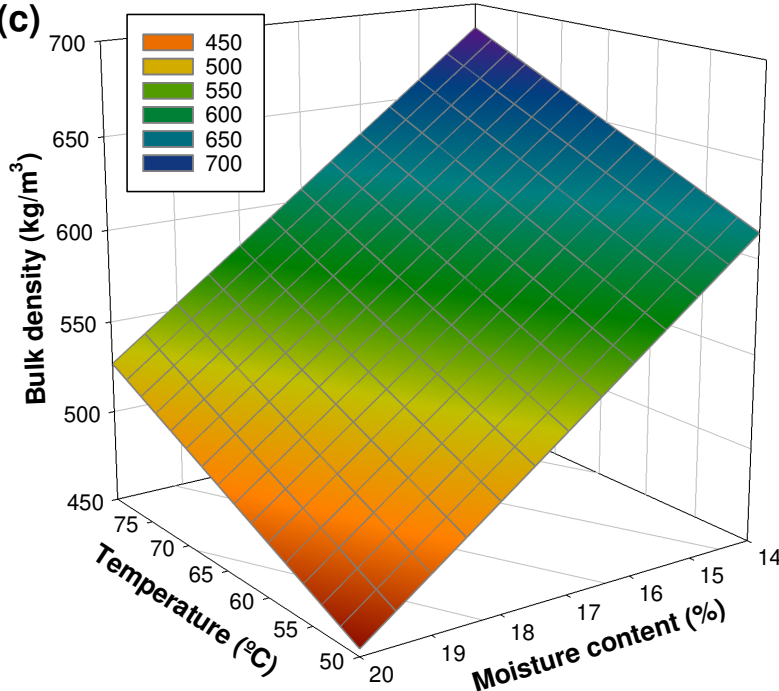

(b)

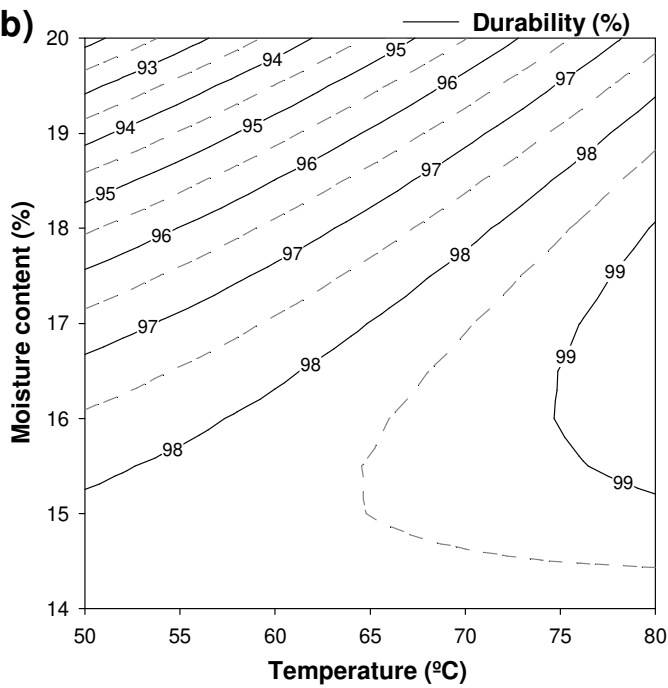

(d)

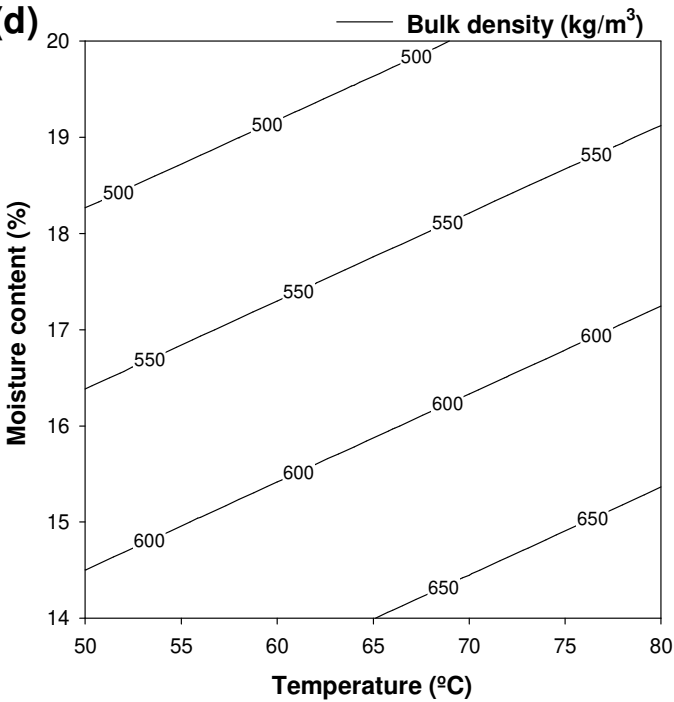

Fig. 1. Response surface and contour plots for durability $(\mathrm{a}, \mathrm{b})$ and bulk density $(\mathrm{c}, \mathrm{d})$ as a function of temperature and biomass moisture content.

The results also show that bulk density (Figs. 1c and 1d), LHV ar (Figs. 2a and 2b) and $\eta_{\text {energy ar }}$ (Figs. 2c and 2d) increase with $\mathrm{T}$, but decrease with MC. This indicates that these variables are favored at higher temperatures and lower biomass moisture contents, so that their highest values are obtained when pelletizing at $80{ }^{\circ} \mathrm{C}$ with $14 \%$ of biomass moisture content. The bulk density value has a very important effect on the energy density and hence on the transportation costs and the storage capacity for both the pellet producer and the end user [7]. Samuelsson et al. [30] also reported that the bulk density of pine sawdust pellets is mainly determined by the biomass moisture content and that its value decreased as the biomass moisture content increased from 8 to $14 \%$. This is explained by the decrease in friction through the die due to the lubricating property of water. A decrease in LHV with increasing biomass moisture content has also been reported [16]. 

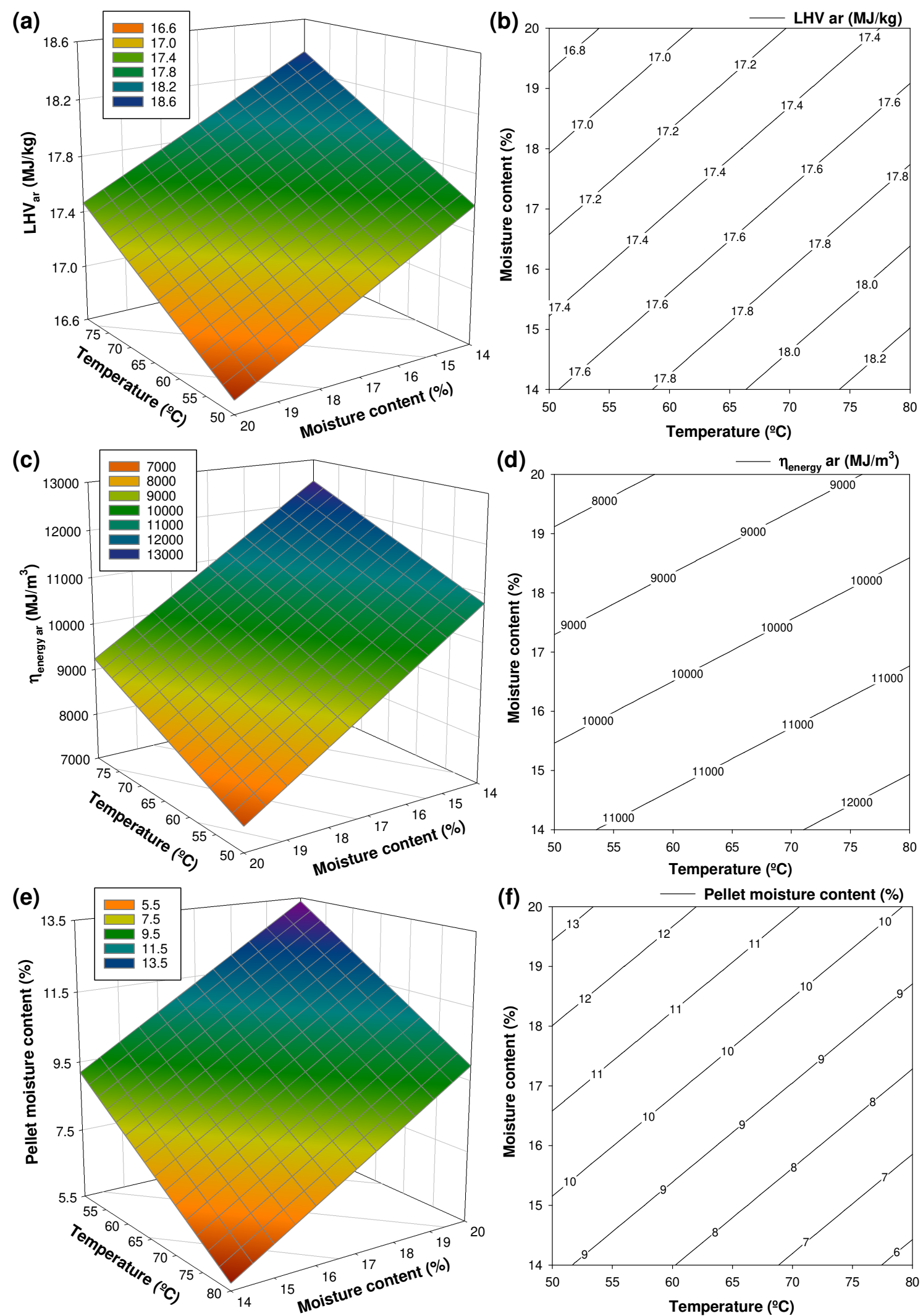

Fig. 2. Response surface and contour plots for lower heating value $\left(\operatorname{LHV}_{a r}\right)(a, b)$, energy density $\left(\eta_{\text {energy ar }}\right)(c, d)$ and pellet moisture content $(\mathrm{e}, \mathrm{f})$ as a function of temperature and biomass moisture content.

Higher temperatures also reduce the pellet moisture content (Figs. 2e and 2f) and the pellet diameter (Figs. 3a and 3b), although this parameter does not influence the pellet length (Figs. 
$3 \mathrm{c}$ and $3 \mathrm{~d}$ ) or pellet density (Figs. 3e and 3f). Higher temperatures could reduce the pellet moisture content due to a higher release of water during the pelletization process. As mentioned above, higher temperatures increased the flexibility of the process: the material was easier to press and a greater adhesive strength was reached which would explain the smaller pellet diameter. On the other hand, lower biomass moisture contents reduce the pellet moisture content, as might be expected, and the diameter and length of the pellet, while increasing pellet density. An excessive MC produces pellets that are too soft since the fluidity of the sample is enhanced, which would explain the greater diameter and length of the pellets. A higher pellet moisture content is therefore obtained when the initial moisture content of the biomass is higher, which leads to a decrease in pellet quality, since a water content in pellets that is too high may negatively influence the efficiency and temperature of combustion.

Some correlations between pellet diameter and pellet length with bulk density were found (Figs. $4 \mathrm{a}$ and $4 \mathrm{~b}$, respectively), with pellets of a shorter diameter and length showing higher bulk density values. The bulk density depends on pellet density and the size-distribution of the pellets. In the present study, pellet density seems to explain a substantial part of bulk density variance, as is shown in Fig. 4c. Indeed, the density of the pellets is an important parameter, since it influences combustion behavior due to the fact that dense particles require longer burnout times [7].

In the light of what has been so far discussed, it can be concluded that the highest pelletization temperature studied, $80^{\circ} \mathrm{C}$, favors pellet quality. However, different biomass moisture conditions are required to optimize the response variables. Thus, a moisture content of $14 \%$ in the biomass sample optimizes the pellet moisture content, bulk density, energy content and energy density, but the durability obtained under these conditions (and when $\mathrm{T}=80{ }^{\circ} \mathrm{C}$ ) is $98.13 \%$, which is lower than the maximum value $(99.4 \%)$, obtained when $\mathrm{MC}=$ $16.6 \%$. 

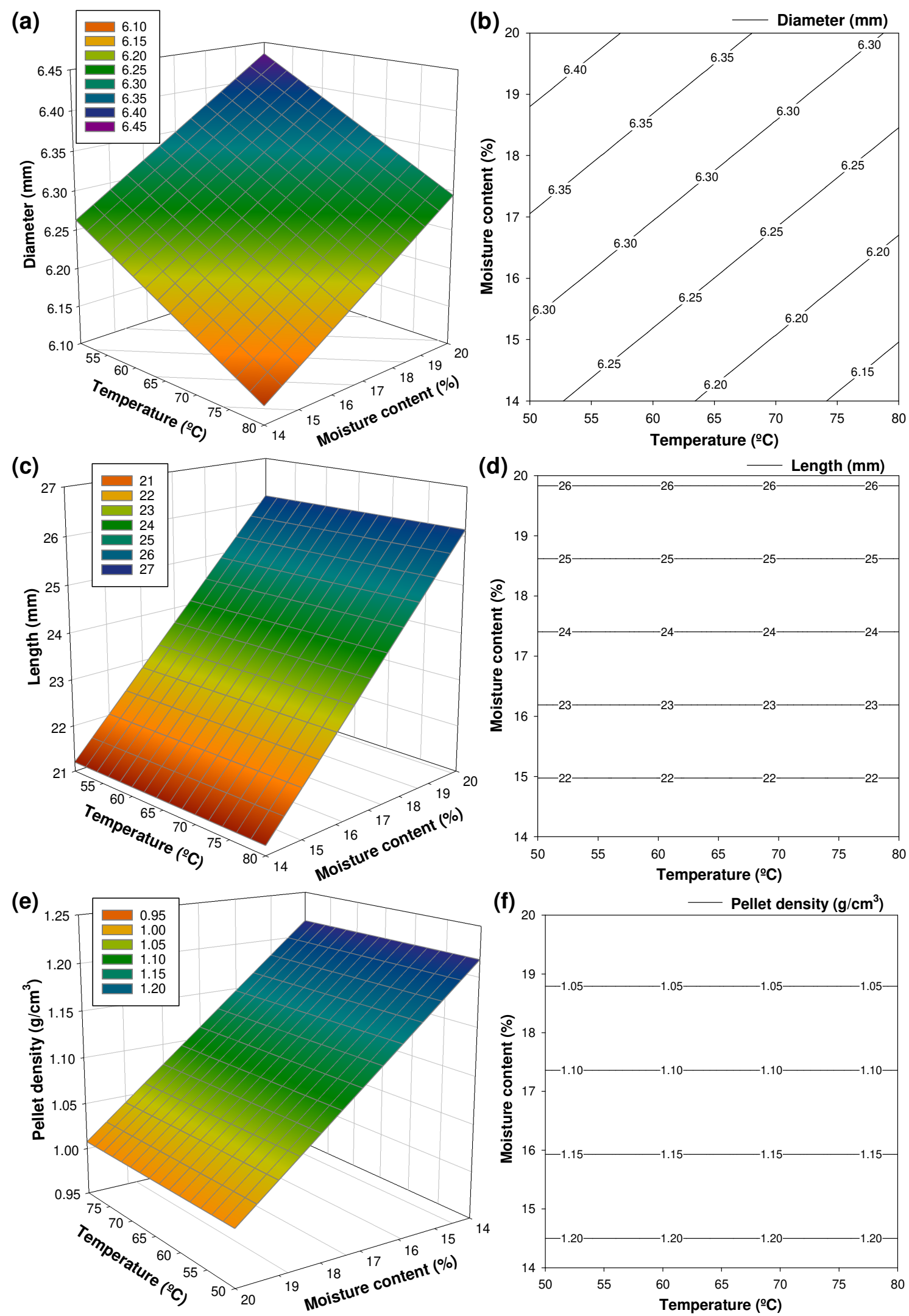

Fig. 3. Response surface and contour plots for diameter (a, b), length (c, d) and pellet density $(e, f)$ as a function of temperature and biomass moisture content. 

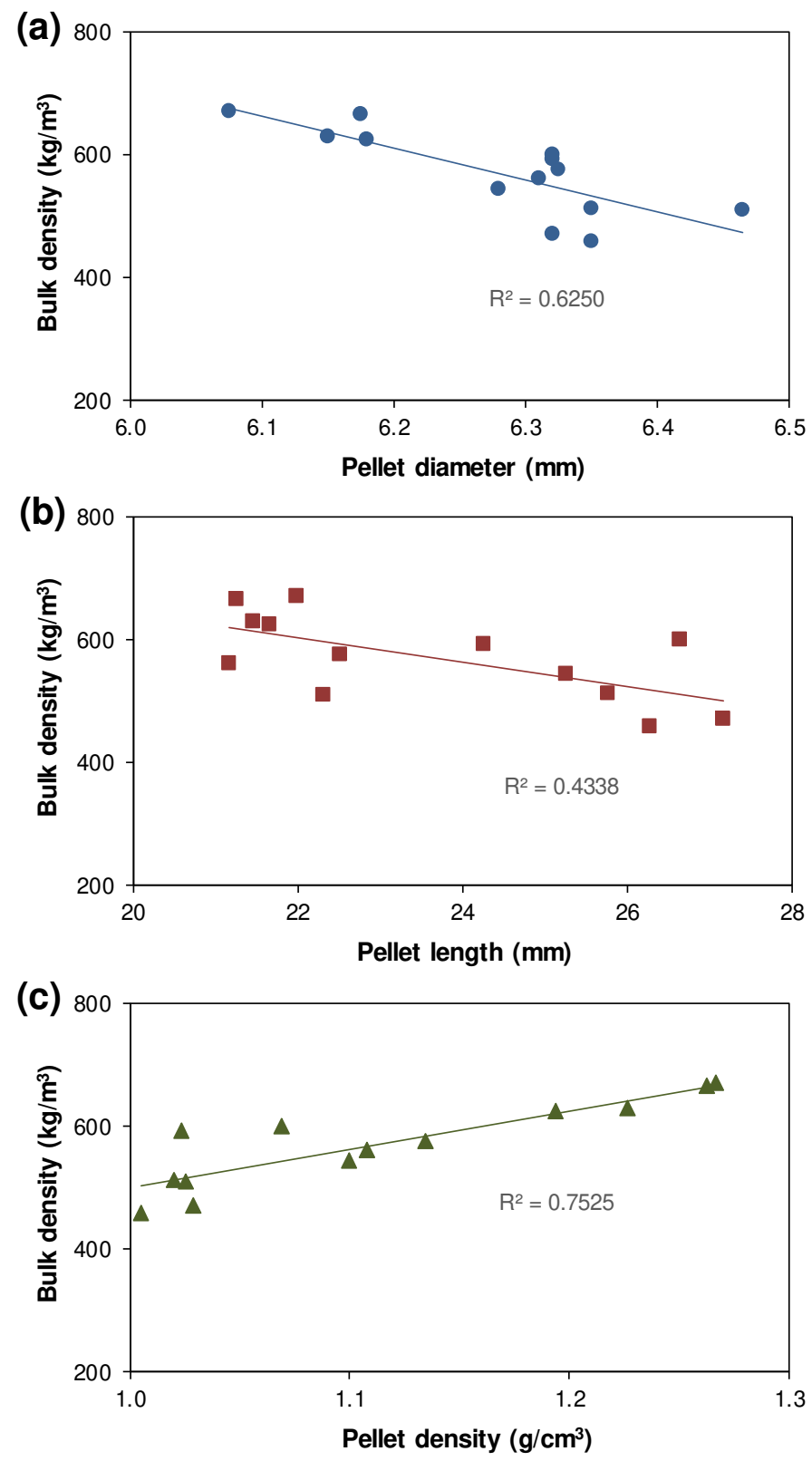

Fig. 4. Relationships of pellet diameter (a), pellet length (b) and pellet density (c) with bulk density.

On the other hand, in relation to the threshold values for industrial pellet quality (Table 1), all the values obtained for $\mathrm{LHV}_{\mathrm{ar}}$, diameter and length of the pellets under the different conditions studied satisfy the given specifications, as shown in Table 3. Therefore, durability, bulk density and pellet moisture content are the parameters that determine whether the pellets produced are suitable for industrial applications. The specifications for industrial pellets establish a minimum of $97.5 \%$ durability for the I1 pellet class, $97 \%$ for the I 2 class and $96.5 \%$ for the I3 class. Likewise, for all three classes of pellet, the minimum value of bulk density required is $600 \mathrm{~kg} / \mathrm{m}^{3}$, whereas the established maximum pellet moisture content is $10 \%$. Fig. 5a shows the threshold values of these variables for pellets of industrial pellet quality. As can 
be seen, bulk density is the most restrictive parameter. Fig. $5 b$ therefore indicates (in gray) the experimental conditions where the values of durability, bulk density and pellet moisture content simultaneously satisfy the requirements of industrial pellets of category I1. If the best conditions for maximizing durability are selected $\left(\mathrm{T}=80{ }^{\circ} \mathrm{C}, \mathrm{MC}=16.6 \%\right)$, the values obtained for bulk density $\left(616 \mathrm{~kg} / \mathrm{m}^{3}\right)$, pellet moisture content $(7.6 \%), \mathrm{LHV}_{\mathrm{ar}}(18 \mathrm{MJ} / \mathrm{kg})$, diameter $(6.2 \mathrm{~mm})$ and length $(23.4 \mathrm{~mm})$ still fulfill the specifications established for industrial pellets.

(a)

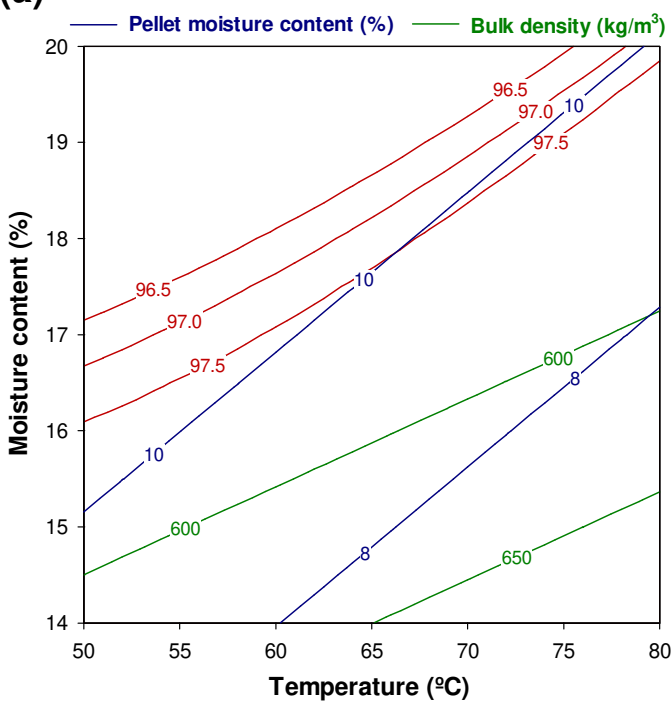

(b)

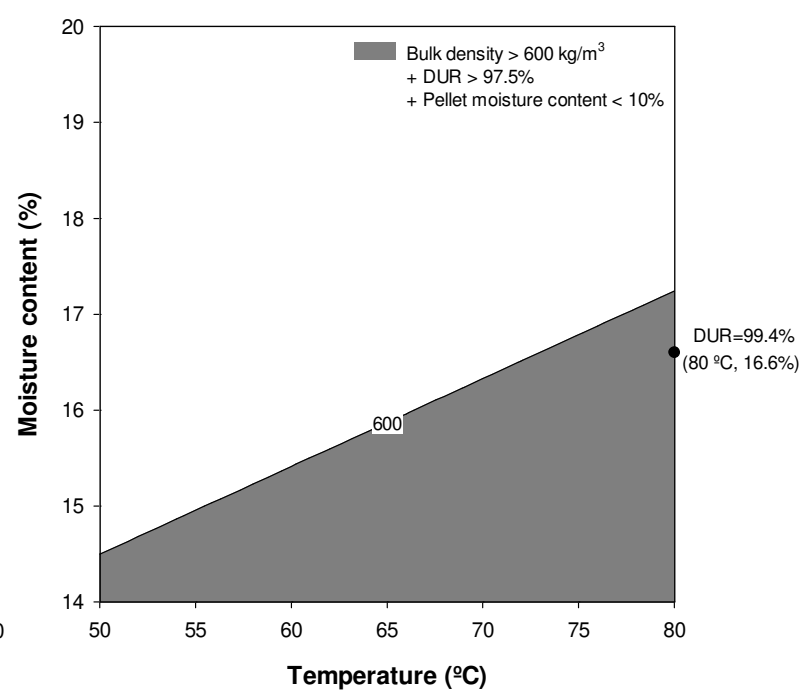

Fig. 5. (a) Thresholds for durability (DUR), bulk density and pellet moisture content according to the industrial pellet specifications; (b) Pelletization temperature and biomass moisture content values that fulfill the specifications.

As shown in Table 3, the only pelletizing conditions (temperature and biomass moisture content) that produce pellets which fulfill the requirements (I1 quality) are: $50^{\circ} \mathrm{C}-14 \%, 65{ }^{\circ} \mathrm{C}$ $14 \%, 80{ }^{\circ} \mathrm{C}-14 \%$ and $80{ }^{\circ} \mathrm{C}-17 \%$. However, if a very high biomass moisture content is used (20\%), high quality pellets cannot be produced due to their low durability and bulk density, and high pellet moisture content. This indicates that at low temperatures, a low biomass moisture content should be employed, while at higher temperatures an intermediate biomass moisture content should be used to obtain pellets of good quality with a greater durability.

\subsection{Pelletization of biomass blends}

Pellets from blends of PIN with other alternative biomasses were produced under the previously determined optimum conditions $\left(\mathrm{T}=80^{\circ} \mathrm{C}, \mathrm{MC}=16.6 \%\right)$. As mentioned above, the quality expected of the pellets from the blends formed according to the $\mathrm{N}, \mathrm{S}$ and ash contents of the raw biomasses is shown in Table 2, since these are the most restrictive chemical properties when selecting the proportion of alternative biomass to use in blends with pine sawdust to obtain pellets of industrial quality. I1 pellets could theoretically be obtained from 
blends of pine sawdust with AS and OS biomasses in proportions of up to $30 \mathrm{wt} \%$, and in the case of the PCL sample in proportions of up to $15 \mathrm{wt} . \%$. If $30 \mathrm{wt} . \%$ of PCL is were used in the blend, I3 pellets would be obtained due to the high $\mathrm{N}$ content of this biomass. Likewise, I3 pellets would be obtained using HS, PKS and SG due to their high N contents. I3 pellets would also be produced if $\mathrm{CD}, \mathrm{CH}$ and $\mathrm{CS}$ were used due to the substantial $\mathrm{N}$ and $\mathrm{S}$ contents of these biomasses. Finally, I3 pellets would be obtained if GP is used due to its high $\mathrm{N}$ and ash contents, and if MIS is added due to its considerable ash content.

Table 6 shows the experimental results for the quality parameters in the pellets obtained from blends of biomass, together with the industrial quality obtained. The ENPlus quality for the pellets formed from the blends has also been included for comparison purposes. In addition, the pelletization temperature is shown here since, although the initial objective was to use a value of $80^{\circ} \mathrm{C}$, an increase in temperature for some blends was not possible due to the fact that it caused the pellets to block the die. In these cases, the temperature at which pellets were obtained is given.

The $\mathrm{LHV}_{\text {ar }}$ for all the blends studied is higher than $16.5 \mathrm{MJ} / \mathrm{kg}$, which is the minimum value required for the three industrial pellet qualities. Likewise, the pellet diameter is higher than $6 \mathrm{~mm}$, while the pellet length is lower than $40 \mathrm{~mm}$, for all the blends, which are the limits established for industrial pellets. Therefore, all the pellets from the biomass blends fulfill the requirements established for these parameters.

Table 6

Experimental results obtained from the pelletization of biomass blends using biomass $\mathrm{MC}=16.6 \%$

\begin{tabular}{|c|c|c|c|c|c|c|c|c|c|c|c|}
\hline $\begin{array}{l}\text { Blend } \\
\text { (wt.\%, db) }\end{array}$ & $\mathrm{T}\left({ }^{\circ} \mathrm{C}\right)$ & $\begin{array}{l}\text { DUR } \\
(\%)\end{array}$ & $\begin{array}{l}\begin{array}{l}\text { Bulk } \\
\text { density }\end{array} \\
\left(\mathrm{kg} / \mathrm{m}^{3}\right)\end{array}$ & $\begin{array}{l}\text { Pellet } \\
\text { moisture } \\
\text { content } \\
(\text { wt. } \%)\end{array}$ & $\begin{array}{l}\mathrm{LHV}_{\mathrm{ar}} \\
(\mathrm{MJ} / \mathrm{kg})\end{array}$ & $\begin{array}{l}\eta_{\text {energy ar }} \\
\left(\mathrm{MJ} / \mathrm{m}^{3}\right)\end{array}$ & $\begin{array}{l}\text { Diameter } \\
(\mathrm{mm})\end{array}$ & $\begin{array}{l}\text { Length } \\
(\mathrm{mm})\end{array}$ & $\begin{array}{l}\begin{array}{l}\text { Pellet } \\
\text { density }\end{array} \\
\left(\mathrm{g} / \mathrm{cm}^{3}\right)\end{array}$ & $\begin{array}{l}\text { Industrial } \\
\text { quality }\end{array}$ & $\begin{array}{l}\text { ENPlus } \\
\text { quality }\end{array}$ \\
\hline $\begin{array}{l}100 \mathrm{PIN} \text { (as } \\
\text { reference) }\end{array}$ & 80 & 99.38 & 616 & 7.5 & 17.962 & 11072 & 6.20 & 23.37 & 1.13 & I1 & A1 \\
\hline 15AS85PIN & 80 & 99.24 & 695 & 7.1 & 17.749 & 12335 & 6.11 & 21.79 & 1.26 & I1 & A1 \\
\hline 30AS70PIN & 65 & 99.10 & 712 & 8.7 & 17.510 & 12472 & 6.25 & 22.20 & 1.26 & I1 & $\mathrm{A} 2$ \\
\hline 10CD90PIN & 80 & 99.21 & 632 & 8.2 & 17.598 & 11124 & 6.21 & 21.84 & 1.20 & $\mathrm{I} 3$ & B \\
\hline 10CH90PIN & 80 & 99.10 & 636 & 8.2 & 17.621 & 11210 & 6.20 & 22.67 & 1.19 & $\mathrm{I} 3$ & $\mathrm{~B}$ \\
\hline 10CS90PIN & 80 & 98.97 & $552 *$ & 9.4 & 17.363 & 9591 & 6.29 & 20.56 & 1.07 & - & - \\
\hline 10GP90PIN & 80 & 99.13 & 704 & 7.8 & 17.820 & 12793 & 6.11 & 20.14 & 1.25 & $\mathrm{I} 3$ & $\mathrm{~B}$ \\
\hline 20GP80PIN & 80 & 98.80 & $588 *$ & 8.6 & 17.579 & 10345 & 6.23 & 23.55 & 1.17 & - & - \\
\hline 15HS85PIN & 65 & 99.35 & 697 & 7.4 & 17.817 & 12424 & 6.16 & 21.92 & 1.21 & $\mathrm{I} 3$ & A2 \\
\hline 15MIS85PIN & 80 & 98.68 & 654 & 8.6 & 17.421 & 11396 & 6.23 & 23.30 & 1.17 & $\mathrm{I} 3$ & B \\
\hline 30MIS70PIN & 80 & $96.35^{*}$ & 660 & 7.3 & 17.564 & 11590 & 6.12 & 17.24 & 1.21 & - & - \\
\hline$\overline{15 \mathrm{OS} 85 \mathrm{PIN}}$ & 80 & 98.80 & 718 & 7.7 & 17.850 & 12810 & 6.15 & 21.00 & 1.22 & I1 & A1 \\
\hline 30OS70PIN & 80 & 97.69 & 628 & 9.3 & 17.593 & 11049 & 6.21 & 18.64 & 1.14 & I1 & A2 \\
\hline 15PCL85PIN & 65 & 99.20 & 707 & 8.3 & 17.682 & 12505 & 6.11 & 18.72 & 1.23 & I1 & A1 \\
\hline 30PCL70PIN & 65 & 98.77 & 710 & 8.4 & 17.683 & 12562 & 6.09 & 15.82 & 1.26 & $\mathrm{I} 3$ & $\mathrm{~A} 2$ \\
\hline 15PKS85PIN & 65 & 98.92 & 716 & 7.9 & 17.817 & 12759 & 6.11 & 18.20 & 1.24 & $\mathrm{I} 3$ & A2 \\
\hline 30PKS70PIN & 65 & 98.07 & 679 & $11.4^{*}$ & 17.141 & 11647 & 6.14 & 20.15 & 1.22 & - & - \\
\hline $15 \mathrm{SG} 85 \mathrm{PIN}$ & 50 & 99.20 & 644 & 9.4 & 17.274 & 11119 & 6.15 & 21.88 & 1.25 & $\mathrm{I} 3$ & $\mathrm{~A} 2$ \\
\hline
\end{tabular}

DUR: durability; LHV: lower heating value; $\eta_{\text {energy: }}$ energy density

ar: as received

*: does not fulfill specifications 
As Fig. 6a shows, the addition of an alternative biomass decreased pellet durability compared to pine sawdust pellets and, in general, a greater reduction in the durability of the pellets resulted when the proportion of alternative biomass in the blend was increased. However, most blends studied still produced pellets of high durability. Only the blend with MIS at $30 \mathrm{wt} . \%$ failed to achieve the minimum threshold values required, indicated by the black lines. Miscanthus has been reported to have a relatively low lignin content (21.2\%) [25], which is considered to be a binding agent due to the fact that lignin softens and flows to the surface, making the particles more flexible and generating more interfacial contact area, which in turn leads to greater adhesive strength [3]. This could therefore account for the lower value of durability obtained for this blend, as was also suggested by Lehmann et al. [44] for blends of $20 \mathrm{wt} . \%$ miscanthus with wood.
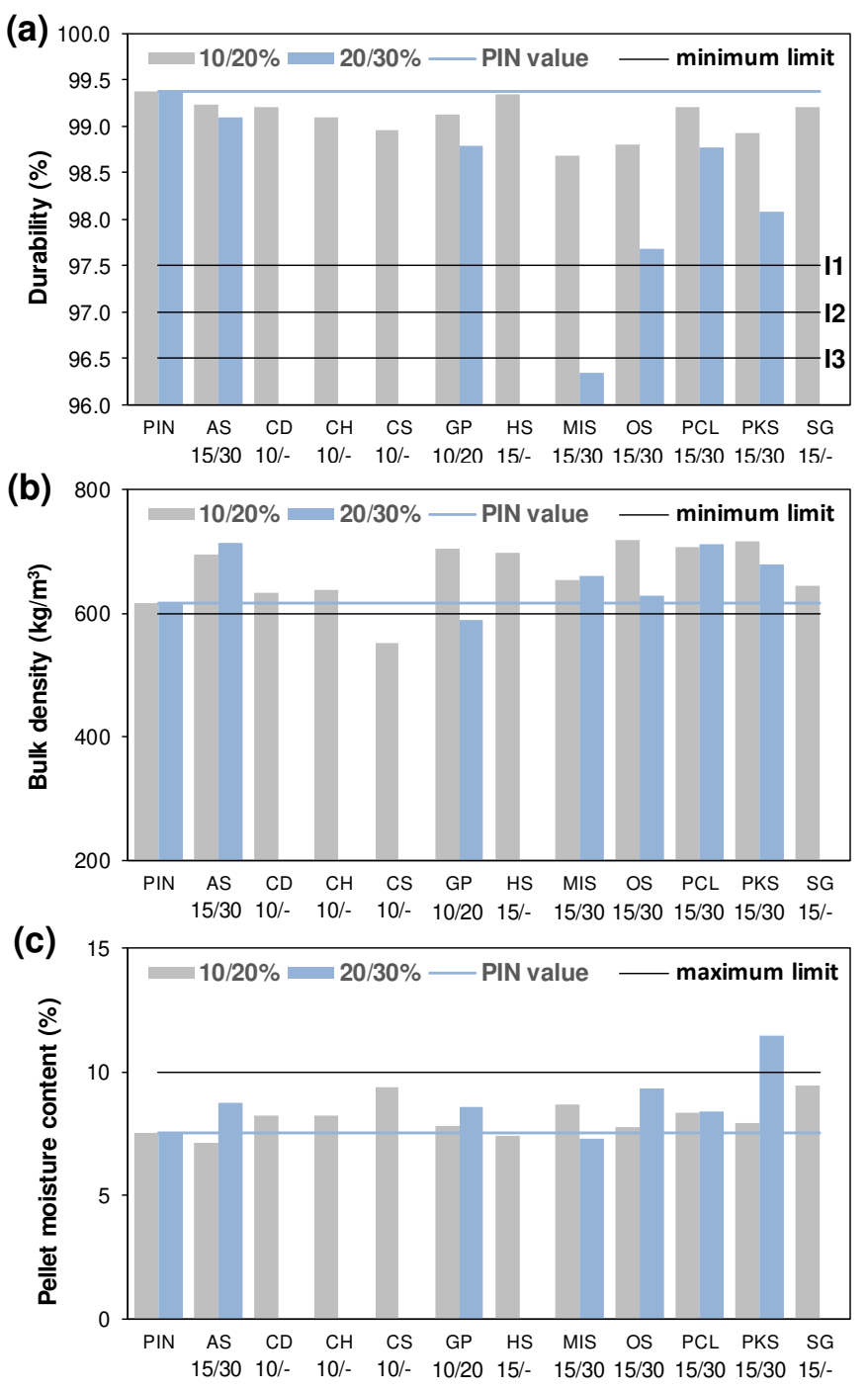

Fig. 6. Durability (a), bulk density (b) and pellet moisture content (c) for the blends of pine sawdust with alternative biomasses. 
Fig. $6 \mathrm{~b}$ shows that the addition of an alternative biomass caused a slight increase in bulk density compared to the pine sawdust pellets for most of the samples. Thus, most of the blends produced pellets with a high bulk density that fulfilled the specifications. However, blends with 10 wt. $\%$ of CS and with $20 \mathrm{wt} . \%$ of GP failed to reach the minimum threshold value required, indicated by the black line.

Fig. $6 \mathrm{c}$ shows the pellet moisture content for all the blends of pine sawdust with the alternative biomasses studied. The pellets obtained from blends presented moisture contents similar to, or slightly higher than, that of the PIN pellets. Most of the blends produced pellets that fulfilled the specifications as regards moisture content. However, pellets from the blend with 30 wt.\% of PKS exceeded the maximum moisture content indicated by the black line.

Although the energy density of the pellets is not included in the quality specifications, its value ranged from 8.7 to $12.8 \mathrm{GJ} / \mathrm{m}^{3}$ (Table 6). If only blends that fulfill all the specifications are considered, the energy density values varied between 11.0 and $12.8 \mathrm{GJ} / \mathrm{m}^{3}$, which agrees with the values reported in literature. Thus, the energy density for pellets from Norway spruce ranged from 12.3 to $14.7 \mathrm{GJ} / \mathrm{m}^{3}$ [41], while for Swedish wood pellets it ranged between 9.7 and $11.3 \mathrm{GJ} / \mathrm{m}^{3}[42]$.

Therefore, the results in Table 6 show that all the blends containing 10 or 15 wt. $\%$ of alternative biomass, except in the case of CS at $10 \mathrm{wt} . \%$, provided pellets of industrial quality. I1 pellets were produced from blends with AS, OS and PCL, while I3 pellets were obtained from blends with CD, CH, GP, HS, MIS, PKS and SG.

However, in the case of blends containing a high proportion of biomass (30 wt.\%), pellets of quality class were only obtained from blends with AS (I1), OS (I1) and PCL (I3). Pellets produced using $30 \mathrm{wt} . \%$ of MIS in the blend could not be classed as industrial pellets according to the quality specifications because of their poor durability. Likewise, pellets from blends with 20 wt.\% of GP and 30 wt.\% of PKS failed to fulfill the specifications due to their low bulk density and high moisture content, respectively. It should be added that high quality I1 pellets were obtained by blending PIN with up to $30 \mathrm{wt} . \%$ of AS and OS, which indicates that these are the least problematic biomasses. However, industrial quality pellets could also be obtained from a variety of biomass types. For comparison purposes, Table 6 shows that it would also be possible to produce ENPlus quality pellets for non-industrial uses from blends of pine sawdust and alternative biomasses. Thus, A1 pellets can be obtained by adding $15 \mathrm{wt}$ \% of AS, OS or PCL, while A2 pellets can be produced by adding 30 wt.\%. Similarly, A2 pellets can be produced with 15 wt.\% of HS, PKS and SG, while B pellets can be produced with low proportions of $\mathrm{CD}, \mathrm{CH}$, GP and MIS. 
Table 6 also shows that some blends produced quality pellets even at low temperatures, as in the case of AS, HS, PCL, PKS and SG, as high temperatures could not be reached due to blockage problems in the die. This suggests that an individual parametric study of the pelletization conditions would be useful if biomass blends are to be used for pelletizing. A higher moisture content in the biomass blend might increase the flexibility of the material and make it easier to press in order to avoid blockage and allow an increase in the pelletization temperature. In any case, the results clearly demonstrate the feasibility of using blends of pine sawdust with alternative biomass feedstocks to produce pellets of industrial quality.

\subsection{Energy requirements for the pelletization of biomass blends}

The energy requirements for grinding and pelletization processes were evaluated for the biomass blends. Fig. 7 shows the energy consumed for grinding and pelletizing PIN and different blends. The biomasses on the $x$ axis are ordered according to total energy consumption (grinding + pelletization).

The pelletization of the blend PIN with SG required a much larger amount of energy than all the other blends for both grinding and pelletization. Mani et al. [43] reported that switchgrass required around three times more energy to hammer mill compared to corn stover due to the fibrous nature of switchgrass. Moreover, Crawford et al. [44] found high pelletization energy requirements for switchgrass, due to its low compressibility, since it is a more fibrous and rigid biomass than other materials.

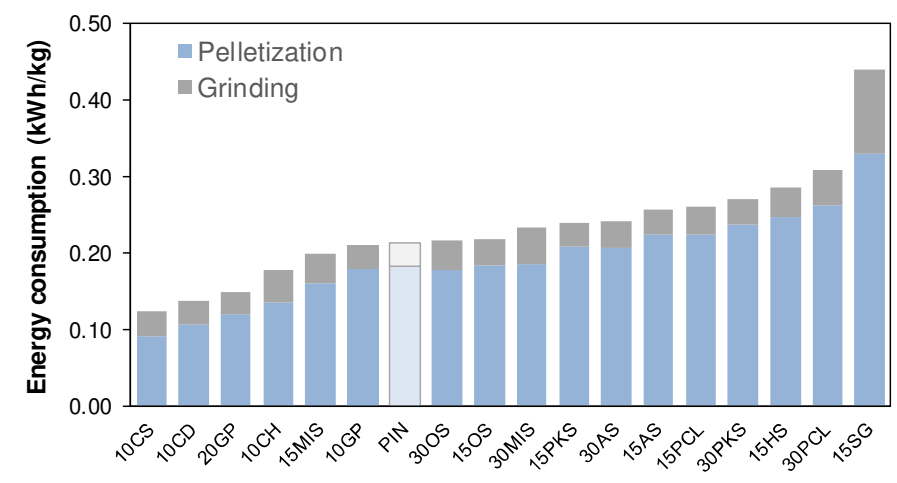

Fig. 7. Energy consumption in the grinding and pelletization processes for the blends of pine sawdust with alternative biomasses.

As mentioned above, it was not possible to use percentages higher than 15 wt. $\%$ of SG in the blends due to blockage problems in the pellet press. HS contents higher than $15 \mathrm{wt} . \%$ were not used for the same reason. For example, during the pelletization of the 15HS85PIN and 15SG85PIN blends, the pellets got blocked in the die before reaching high temperatures, as indicated in Table 6. Likewise, for blends with 15 wt.\% of PCL and PKS, and with $30 \mathrm{wt} . \%$ of 
AS, PKS and PCL, high pelletization temperatures could not be reached. All of these blend samples showed high energy consumption values, as shown in Fig. 7. The energy required by the extruding process is mainly the result of friction between the material and the matrix [6]. In these cases, therefore the increased friction due to low temperature probably contributed to the higher energy consumption during the pelletization process. Future studies could be aimed at ascertaining whether the initial biomass moisture content could be adjusted to facilitate the pelletization of these blends so as to reduce energy requirements without undermining the quality of the pellets.

It can be seen that the total energy requirements for the blends of pine sawdust with CS, CD, GP, CH and MIS (at 15 wt.\%) were lower than for PIN, while the blends with OS showed a similar energy consumption to that of PIN. However, the blends with MIS (at $30 \mathrm{wt} \%$ ), AS, PKS and PCL increased the energy requirements slightly. In the grinding process, the blends with most of the biomasses reported an energy consumption very similar to, or only slightly higher (3-7\%) than, that of PIN. Only the blends with CH, MIS, PCL and HS showed a more marked increase in energy consumption during grinding. In contrast, the blend of PIN with 15 wt.\% of SG showed an extremely high energy requirement in grinding.

The energy consumption associated with the pelletization process followed a similar tendency to that of the total energy requirements. In fact, the pelletization stage required the greatest share (75-88\%) in the consumption of energy in the entire process for all the biomasses. Although the lowest energy consumption corresponded to the blend with $\mathrm{CS}$, it failed to produce pellets of the quality class due to the low bulk density obtained. Neither did blends of pine sawdust with high proportions of GP, MIS and PKS yield pellets of quality. The results then show that the use of most of the alternative biomass materials in blends with pine sawdust, i.e., $\mathrm{CD}, \mathrm{CH}$, MIS, GP and OS, would not make the overall cost of pelletization more than when using only PIN. However, in the case of PKS, AS, PCL, HS and SG, the cost of the energy required for the grinding and pelletizing processes under the conditions studied would be higher than when using just PIN. Less friction in the die might be achieved if the pelletization conditions were changed in order to reduce energy consumption in the case of pellets obtained under low temperatures.

Although an increase in friction in the die due to the temperature may have been the main cause for of the higher energy consumption for in the case of some samples, differences between the biomasses could also have been influenced to some extent by their chemical compositions and the amounts of lignin, hemicellulose and extractives from biomass species. Extractives can act as lubricants that reduce friction in the die, resulting in a lower bulk density and energy 
consumption [30]. Indeed high extractive content in the raw biomass has been reported to reduce the energy needed for producing pellets, as well as bulk density [6]. In summary a positive correlation between the energy consumption during the pelletization process and the bulk density of the pellets has been found in the present work (Fig. 8a) (the 15SG85PIN blend is excluded due its particular behavior). Thus, both the low energy consumption and the low bulk density of the blends can be ascribed to the high extractive content. In the present work, a high energy consumption during pelletization compared to PIN was observed for biomasses of the hard wood type (olive stones, pine kernel shells, almond shells, pine cone leafs and hazelnut shells), while a low energy consumption was recorded for biomasses with a more softherbaceous character (cocoa shells, coffee dregs, coffee husks, miscanthus and grape pomace). Low power demand values were also found in herbaceous species by Castellano et al. [45], which they attributed to the fact that herbaceous materials contain more extractives than woody materials.
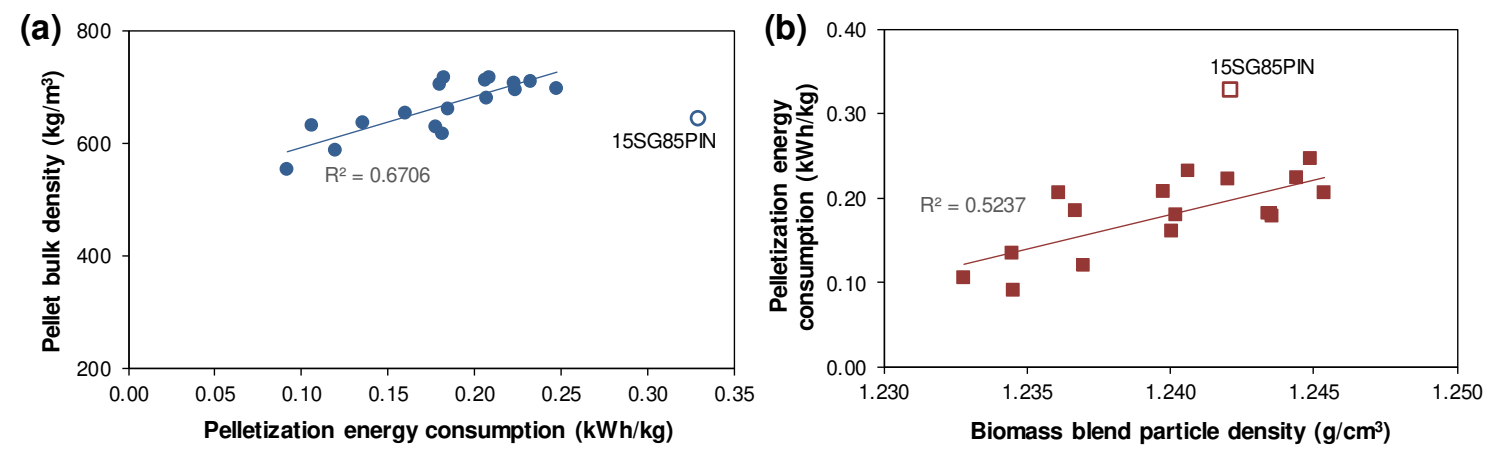

Fig. 8. (a) Relationship between energy consumption in the pelletization process and pellet bulk density. (b) Relationship between biomass blend particle density and energy consumption in the pelletization process. The blend 15SG85PIN has been excluded from the regression analysis.

A positive correlation between the particle density of the biomass blends (its true density) and energy consumption during pelletization was also found in the present work (Fig. 8b). Crawford et al. [44] claimed that the pelletization energy is correlated with the compressibility of the biomass feedstock. As mentioned above, these authors found high pelletization energy requirements for switchgrass, due to its poor compressibility resulting from the fibrous and rigid nature of this biomass. Particle density was measured as He density [46] and is defined as the mass per unit volume occupied by the solid constituent of the sample. Some physical properties of raw biomass particles such as particle size and particle density content have been claimed to have an influence on the compressibility of the material [47]. 


\section{Conclusions}

Response surface methodology was successfully applied to evaluate the combined effect of pelletization temperature and biomass moisture content upon pine sawdust pellet quality on the basis of specifications established for industrial pellets by the ISO 17225-2 norm. Both factors had a significant effect on pellet quality, but the variable that had the greatest influence on the response variables studied was biomass moisture content. The optimum pelletization conditions were found to be a temperature of $80^{\circ} \mathrm{C}$ and a biomass moisture content of $16.6 \%$. These produced pellets with the greatest durability (99.4\%), besides fulfilling the values of bulk density, pellet moisture content, lower heating value, diameter and length required for industrial pellets.

Blends of pine sawdust and eleven residual alternative biomasses were also tested to obtain industrial quality pellets. Nitrogen and ash contents were found to be the most restrictive parameters when selecting the proportion of biomass to be added to the blends with pine sawdust in order to produce pellets of industrial quality. However, to produce industrial category pellets, blends of pine sawdust with different percentages of residual biomasses restricted to: less than $30 \mathrm{wt} . \%$ for almond shells, coffee dregs, olive stones and pine cone leafs; less than 15 wt.\% for hazelnut shells, miscanthus, pine kernel shells and switchgrass; and less than 10 wt.\% for coffee husks and grape pomace. Pellets obtained using cocoa shells could not be included in industrial pellet classes due to their low bulk density.

Energy consumption during grinding and pelletization was also evaluated. The biomass binder had a strong impact on the energy consumption: blends with $\mathrm{CD}$, CS or GP noticeably reduce energy consumption compared to when just pine sawdust is used. The overall energy consumption varied from $0.12 \mathrm{kWh} / \mathrm{kg}$ to $0.44 \mathrm{kWh} / \mathrm{kg}$, with pine sawdust, taken as reference, in an intermediate position $(0.22 \mathrm{kWh} / \mathrm{kg})$. In addition, energy consumption of the blends showed a positive correlation with pellet bulk density and the biomass blend particle density.

The results obtained support the use of alternative biomass residues blended with woody biomass for producing pellets of industrial quality, that would provide an environmentally friendly waste management option able to meet the needs of a rapidly growing pellet market.

\section{Acknowledgements}

Financial support from the CSIC (Spain) (Project PIE 201780E057) and from the Gobierno del Principado de Asturias (PCTI, Ref. IDI/2018/000115) with co-funding from the European Regional Development Fund (ERDF) is gratefully acknowledged. 


\section{References}

[1] Kaliyan N, Vance Morey R. Factors affecting strength and durability of densified biomass products. Biomass Bioenerg 2009;33:337-59. https://doi.org/10.1016/j.biombioe.2008.08.005. [2] Nielsen NPK, Gardner DJ, Poulsen T, Felby C. Importance of temperature, moisture content, and species for the conversion process of wood residues into fuel pellets. Wood Fiber Sci 2009;41:414-25.

[3] Stelte W, Holm JK, Sanadi AR, Barsberg S, Ahrenfeldt J, Henriksen UB. A study of bonding and failure mechanisms in fuel pellets from different biomass resources. Biomass Bioenerg 2011;35:910-8. https://doi.org/10.1016/j.biombioe.2010.11.003.

[4] EPC. European Pellet Council, A European Success Story, https://epc.bioenergyeurope.org/about-pellets/pellets-basics/wood-pellets-a-european-successstory/; 2018 (accessed 12 November 2018).

[5] EPC. European Pellet Council, Pellet Statistics, https://epc.bioenergyeurope.org/aboutpellets/pellets-statistics/; 2018 (accessed 12 November 2018).

[6] Filbakk T, Skjevrak G, Høibø O, Dibdiakova J, Jirjis R. The influence of storage and drying methods for Scots pine raw material on mechanical pellet properties and production parameters. Fuel Process Technol 2011;92:871-8.

https://doi.org/10.1016/j.fuproc.2010.12.001.

[7] Obernberger I, Thek G. Physical characterisation and chemical composition of densified biomass fuels with regard to their combustion behaviour. Biomass Bioenerg 2004;27:653-69. https://doi.org/10.1016/j.biombioe.2003.07.006.

[8] ISO. ISO 17225-2:2014. Solid biofuels, Fuel specifications and classes, Part 2: Graded wood pellets. International Organization for Standardization, ISO; 2014.

[9] EPC. ENplus Handbook, version 3. Quality Certification Scheme For Wood Pellets, Part 3: Pellet Quality Requirements. Belgium: European Pellet Council (EPC) c/o AEBIOM European Biomass Association; 2015.

[10] Thrän D, Peetz D, Schaubach K (2017). Global Wood Pellet Industry and Trade Study 2017. IEA Bioenergy Task 40. http://task40.ieabioenergy.com/wpcontent/uploads/2013/09/IEA-Wood-Pellet-Study final-2017-06.pdf.

[11] Monedero E, Portero H, Lapuerta M. Pellet blends of poplar and pine sawdust: Effects of material composition, additive, moisture content and compression die on pellet quality. Fuel Process Technol 2015;132:15-23. https://doi.org/10.1016/i.fuproc.2014.12.013.

[12] Chew KW, Chia SR, Yap YJ, Ling TC, Tao Y, Show PL. Densification of food waste compost: Effects of moisture content and dairy powder waste additives on pellet quality. Process Saf Environ Prot 2018;116:780-6. https://doi.org/10.1016/j.psep.2018.03.016. [13] Nunes LJR, Matias JCO, Catalão JPS. Mixed biomass pellets for thermal energy production: A review of combustion models. Appl Energy 2014;127:135-40.

https://doi.org/10.1016/j.apenergy.2014.04.042.

[14] Prvulovic S, Gluvakov Z, Tolmac J, Tolmac D, Matic M, Brkic M. Methods for Determination of Biomass Energy Pellet Quality. Energy Fuels 2014;28:2013-8.

https://doi.org/10.1021/ef402361k.

[15] Pradhan P, Mahajani SM, Arora A. Production and utilization of fuel pellets from biomass: A review. Fuel Process Technol 2018;181:215-32.

https://doi.org/10.1016/j.fuproc.2018.09.021.

[16] Ishii K, Furuichi T. Influence of moisture content, particle size and forming temperature on productivity and quality of rice straw pellets. Waste Manage 2014;34:2621-6.

https://doi.org/10.1016/j.wasman.2014.08.008.

[17] Liu Z, Liu Xe, Fei B, Jiang Z, Cai Z, Yu Y. The properties of pellets from mixing bamboo and rice straw. Renew Energy 2013;55:1-5.

https://doi.org/10.1016/j.renene.2012.12.014. 
[18] Said N, Abdel daiem MM, García-Maraver A, Zamorano M. Influence of densification parameters on quality properties of rice straw pellets. Fuel Process Technol 2015;138:56-64. https://doi.org/10.1016/j.fuproc.2015.05.011.

[19] Stelte W, Holm JK, Sanadi AR, Barsberg S, Ahrenfeldt J, Henriksen UB. Fuel pellets from biomass: The importance of the pelletizing pressure and its dependency on the processing conditions. Fuel 2011;90:3285-90. https://doi.org/10.1016/j.fuel.2011.05.011. [20] Liu Z, Quek A, Balasubramanian R. Preparation and characterization of fuel pellets from woody biomass, agro-residues and their corresponding hydrochars. Appl Energy

2014;113:1315-22. https://doi.org/10.1016/j.apenergy.2013.08.087.

[21] Tabil Jr L, Sokhansanj S. Process Conditions Affecting the Physical Quality of Alfalfa Pellets. Appl Eng Agric 1996;12:345-50. https://doi.org/10.13031/2013.25658.

[22] Fasina OO. Physical properties of peanut hull pellets. Bioresour Technol 2008;99:125966. https://doi.org/10.1016/j.biortech.2007.02.041.

[23] Gil MV, Oulego P, Casal MD, Pevida C, Pis JJ, Rubiera F. Mechanical durability and combustion characteristics of pellets from biomass blends. Bioresour Technol 2010;101:885967. https://doi.org/10.1016/j.biortech.2010.06.062.

[24] Mani S, Tabil LG, Sokhansanj S. Effects of compressive force, particle size and moisture content on mechanical properties of biomass pellets from grasses. Biomass Bioenerg 2006;30:648-54. https://doi.org/10.1016/j.biombioe.2005.01.004.

[25] Zamorano M, Popov V, Rodríguez ML, García-Maraver A. A comparative study of quality properties of pelletized agricultural and forestry lopping residues. Renew Energy 2011;36:3133-40. https://doi.org/10.1016/j.renene.2011.03.020.

[26] Carone MT, Pantaleo A, Pellerano A. Influence of process parameters and biomass characteristics on the durability of pellets from the pruning residues of Olea europaea L. Biomass Bioenerg 2011;35:402-10. https://doi.org/10.1016/j.biombioe.2010.08.052.

[27] Barbanera M, Lascaro E, Stanzione V, Esposito A, Altieri R, Bufacchi M.

Characterization of pellets from mixing olive pomace and olive tree pruning. Renew Energy 2016;88:185-91. https://doi.org/10.1016/j.renene.2015.11.037.

[28] García R, González-Vázquez MP, Pevida C, Rubiera F. Pelletization properties of raw and torrefied pine sawdust: Effect of co-pelletization, temperature, moisture content and glycerol addition. Fuel 2018;215:290-7. https://doi.org/10.1016/j.fuel.2017.11.027.

[29] Huang Y, Finell M, Larsson S, Wang X, Zhang J, Wei R, et al. Biofuel pellets made at low moisture content - Influence of water in the binding mechanism of densified biomass.

Biomass Bioenerg 2017;98:8-14. https://doi.org/10.1016/j.biombioe.2017.01.002.

[30] Samuelsson R, Larsson SH, Thyrel M, Lestander TA. Moisture content and storage time influence the binding mechanisms in biofuel wood pellets. Appl Energy 2012;99:109-15. https://doi.org/10.1016/j.apenergy.2012.05.004.

[31] Harun NY, Afzal MT. Effect of Particle Size on Mechanical Properties of Pellets Made from Biomass Blends. Procedia Eng 2016;148:93-9.

https://doi.org/10.1016/j.proeng.2016.06.445.

[32] Stasiak M, Molenda M, Bańda M, Wiącek J, Parafiniuk P, Gondek E. Mechanical and combustion properties of sawdust - Straw pellets blended in different proportions. Fuel Process Technol 2017;156:366-75. https://doi.org/10.1016/j.fuproc.2016.09.021.

[33] Agar DA, Rudolfsson M, Kalén G, Campargue M, Da Silva Perez D, Larsson SH. A systematic study of ring-die pellet production from forest and agricultural biomass. Fuel Process Technol 2018;180:47-55. https://doi.org/10.1016/j.fuproc.2018.08.006.

[34] García Fernández R, Pizarro García C, Gutiérrez Lavín A, Bueno de las Heras JL, Pis JJ. Influence of physical properties of solid biomass fuels on the design and cost of storage installations. Waste Manage 2013;33:1151-7. https://doi.org/10.1016/j.wasman.2013.01.033. 
[35] Erol M, Haykiri-Acma H, Küçükbayrak S. Calorific value estimation of biomass from their proximate analyses data. Renew Energy 2010;35:170-3.

https://doi.org/10.1016/j.renene.2009.05.008.

[36] Pis JJ, Cagigas A, Simón P, Lorenzana JJ. Effect of aerial oxidation of coking coals on the technological properties of the resulting cokes. Fuel Process Technol 1988;20:307-16. https://doi.org/10.1016/0378-3820(88)90029-X.

[37] Pradhan P, Arora A, Mahajani SM. Pilot scale evaluation of fuel pellets production from garden waste biomass. Energy for Sustainable Development 2018;43:1-14.

https://doi.org/10.1016/j.esd.2017.11.005.

[38] Bezerra MA, Santelli RE, Oliveira EP, Villar LS, Escaleira LA. Response surface methodology (RSM) as a tool for optimization in analytical chemistry. Talanta 2008;76:96577. http://dx.doi.org/10.1016/j.talanta.2008.05.019.

[39] Myers RH, Montgomery DC. Response Surface Methodology: Process and Product in Optimization Using Designed Experiments. first ed. New York: John Wiley \& Sons, Inc.; 1995.

[40] Baş D, Boyacı İH. Modeling and optimization I: Usability of response surface methodology. J Food Eng 2007;78:836-45. http://dx.doi.org/10.1016/j.jfoodeng.2005.11.024. [41] Larsson SH, Rudolfsson M, Nordwaeger M, Olofsson I, Samuelsson R. Effects of moisture content, torrefaction temperature, and die temperature in pilot scale pelletizing of torrefied Norway spruce. Appl Energy 2013;102:827-32.

https://doi.org/10.1016/j.apenergy.2012.08.046.

[42] Obernberger I, Thek G. The Pellet Handbook - the production and thermal utilisation of biomass pellets. London, Washington DC: Earthscan Ltd.; 2010.

[43] Mani S, Tabil LG, Sokhansanj S. Grinding performance and physical properties of wheat and barley straws, corn stover and switchgrass. Biomass Bioenerg 2004;27:339-52.

https://doi.org/10.1016/j.biombioe.2004.03.007.

[44] Crawford NC, Ray AE, Yancey NA, Nagle N. Evaluating the pelletization of "pure" and blended lignocellulosic biomass feedstocks. Fuel Process Technol 2015;140:46-56.

https://doi.org/10.1016/i.fuproc.2015.08.023.

[45] Castellano JM, Gómez M, Fernández M, Esteban LS, Carrasco JE. Study on the effects of raw materials composition and pelletization conditions on the quality and properties of pellets obtained from different woody and non woody biomasses. Fuel 2015;139:629-36. https://doi.org/10.1016/j.fuel.2014.09.033.

[46] De S, Agarwal AK, Moholkar VS, Thallada B. Coal and Biomass Gasification: Recent Advances and Future Challenges: Springer Singapore; 2017.

[47] Rezaei H, Sokhansanj S. Physical and thermal characterization of ground bark and ground wood particles. Renew Energy 2018;129:583-90.

https://doi.org/10.1016/j.renene.2018.06.038. 